\title{
Fabrication, characterization, and electrochemical performance of the HDPE/sepiolite nanocomposite as a novel separator for Li-ion batteries
}

\author{
M. Kh. Mohammadzad ${ }^{1}$, G. Pircheraghi ${ }^{1 *}$, . Sharifi $^{2}$ \\ ${ }^{1}$ Polymeric Materials Research Group (PMRG), Department of Materials Science and Engineering, Sharif University of \\ Technology, P.O.Box: Azadi Ave., Tehran, Iran \\ ${ }^{2}$ Department of Materials Science and Engineering, Sharif University of Technology, P.O.Box: Azadi Ave., Tehran, Iran
}

Received 18 April 2021; accepted in revised form 8 July 2021

\begin{abstract}
Separators are one of the most critically important components of lithium-ion batteries to ensure the safe performance of the battery. Commercial polyolefin separators have high thermal shrinkage and low electrolyte uptake, which confines the application of the battery. By using the thermally induced phase separation (TIPS) method, we successfully prepared HDPE/sepiolite nanocomposite separators with high thermal stability and electrolyte wettability. The sepiolite nanofibers are modified with the Vinyltriethoxysilane (VTES) as a coupling agent for better dispersion and interaction in the HDPE matrix. The purpose of fabricating this separator is to decrease the thermal shrinkage and increasing electrolyte uptake of the HDPE separator. The separator electrolyte uptake increased from $86 \%$ for pure HDPE separator to $120 \%$ for HDPE/sepiolite separator. The thermal shrinkage results indicated that the sample with $3 \mathrm{wt} \%$ of sepiolite after remaining for $30 \mathrm{~min}$ at $150{ }^{\circ} \mathrm{C}$ had only $5 \%$ shrinkage compared with $93 \%$ of pure HDPE. The results of electrochemical performance showed that the ion conductivity of the separator increased from $0.36 \cdot 10^{-3} \mathrm{~S} \cdot \mathrm{cm}^{-1}$ for the pure HDPE to $0.9 \cdot 10^{-3} \mathrm{~S} \cdot \mathrm{cm}^{-1}$ for the nanocomposite separator. The results of cyclability and rate performance showed that the cell assembled with a separator having $3 \mathrm{wt} \%$ modified sepiolite has a higher discharge capacity than the cell assembled with a pure HDPE separator.
\end{abstract}

Keywords: nanocomposites, polymer membranes, battery separators, sepiolite nanofibers

\section{Introduction}

Increasing global demand for energy on the one hand and warnings of declining fossil fuels and non-renewable energy sources on the other have increased the necessity for green and renewable energy sources such as solar energy, wind energy, geothermal energy, etc. [1-6]. Furthermore, the pollution increment, which mainly originated from $\mathrm{CO}_{2}$ content in the atmosphere, has attracted technological researchers to substitute combustion-engine cars with hybrid vehicles. Technical successes have led to energy storage systems such as electrochemical batteries [7-12].
Among the various types of batteries, lithium-ion batteries lead the way due to their high power and energy density, high open-circuit voltage, high capacity, low self-discharging, biocompatibility, and long cycle life [13-16]. These batteries are widely used in various mobile electronic devices, cell phones, laptops, and more recently in electric and hybrid vehicles [1]. Lithium-ion batteries consist of four main components, including anode, cathode, electrolyte, and separator $[17,18]$. In polymeric lithium-ion batteries, it is a membrane separator that is placed between the anode and the cathode and is a vital component [19, 
20]. The first application of the separator is to effectively transfer electrical charge carriers (ions) between two electrodes as an efficient ionic conductor and to prevent electrical contact between the electrodes as a good electrical insulator [20,21].

Microporous separators are manufactured by various methods, the most important of which are: 1) extrusion melting-extension process and 2) phase separation process. In the extrusion melting-extension process, the intended polymer is melted along with the additives in the extruder and removed as a film. Then biaxial stretching is applied to the film, and the desired membrane is created [22-24]. In the phase separation process, polymer, lubricant, and other additives are mixed to form a homogeneous compound inside the internal mixer or by solution melting in a glass reactor above the polymer processing temperature over a period of time. The mixed melt compound is then turned into a film by utilizing different methods such as hot pressing. Finally, the microporous membrane is prepared through phase separation and extraction of lubricant [25-27]. One of the phase separation techniques is the thermally induced phase separation (TIPS) method. In the TIPS process, the homogeneous polymer/diluent mixture was prepared by melt mixing at a relatively high temperature, then the resulting mixture was pressurized using a press and cooled to obtain a polymer/solvent mixture sheet. The TIPS method has the following advantages relative to other methods: a) the porous structure of the separator can be easily controlled, b) the separator is produced with high porosity, and c) different types of modifiers and additives can be added to the polymer compound in the first step [28-30]. A vast volume of micro-porous separators is manufactured using polyolefin polymers [17, 31,32]. Polyolefin separators, including polyethylene (PE) and polypropylene (PP), have suitable mechanical properties, high electrochemical stability, ease of processing, and low cost. They are compatible with cell chemistry and can withstand several charge-discharge cycles without significant reduction in physical and chemical properties [21, 33, 34]. However, these separators have some drawbacks, such as low thermal stability and poor wettability with the electrolyte, which reduces the battery performance $[35,36]$. Therefore, these separators are usually modified by surface coating, surface grafting, and blending techniques. In surface modification by coating and grafting methods, the modified sites usually deprive the pores inside the separator because of the limited diffusion ability of the modifying agents into the separator pores. By bulk modification method, both the surface and internal pores of the separator have a chance to be modified at the same time. However, to date, studies on the bulk modification of polyolefin separators have rarely been investigated [7, 16, 32, 34, 37]. As a pioneer work, Yoneda et al. [38] manufactured a polyethylene separator with the PE, Silica, and DOP component by phase-separation method. Liao et al. [23] prepared a hydrophilic microporous separator of polyethylene/methylcellulose composite by utilizing a thermally-induced phase separation method to be used in lithium-ion batteries. To reduce interfacial resistance, Jeong and Kim [39] applied acrylonitrile methyl methacrylate coating to the polyethylene separator by using immersing and phase inversion methods. Zhu et al. [40] prepared the ceramic $\left(\mathrm{SiO}_{2}\right)$-grafted $\mathrm{PE}$ separator by electron beam irradiation to improve thermal stability and wettability of the commercial PE separator. Sepiolite is a hydrated magnesium silicate. Having a high specific surface area and being porous, with the unusual shape of the particles, this clay causes high absorption capability and colloidal properties [41-44]. Unlike other clays, sepiolite particles have needle shape morphology, and a high specific area $\left(300 \mathrm{~m}^{2} / \mathrm{gr}\right)$, also a high density of silanol $(\mathrm{SiOH})$ groups, which justifies the considerable hydrophilicity of this clay [45-48]. Sepiolite, as a porous needleshaped ceramic reinforcement, can simultaneously increase the thermal stability of the separator and form a better wettability of the separator [49-51]. In the present study, an attempt has been made to develop and evaluate separators with improved thermal and mechanical properties and electrolyte uptake using the potential of sepiolite nanofibers. These separators are made by the thermally-induced phase separation method, which is one of the best methods to make separators with high porosity and suitable porosity size. To the best of our knowledge, Polyethylene/sepiolite nanocomposite separators, which have not yet been manufactured, have a combination of the excellent chemical stability of polyethylene and the high hydrophilicity and suitable mechanical properties of sepiolite. A key point in polyethylene/ sepiolite nanocomposite separators is to create good compatibility between hydrophobic polymer and hydrophilic sepiolite by modifying the sepiolite nanofibers with vinyltriethoxysilane. 


\section{Experimental}

\subsection{Materials}

High-density polyethylene (HDPE-EX3, melting flow rate index $=0.45 \mathrm{~g} / 10 \mathrm{~min}$, melting point $=127^{\circ} \mathrm{C}$, density $=0.945 \mathrm{~g} / \mathrm{cm}^{3}$, yield stress $=22 \mathrm{MPa}$ ) manufactured by Amir-Kabir petrochemical company (Iran) was used as separator matrix. This polymer is a raw powder from a reactor that has no history of thermal treatment after the polymerization process, and no additives have been added to it to improve the ease of processing. The sepiolite nanofibers used in the project were manufactured by Dorkav mineral company, which extracts sepiolite from a mine around the city of Fariman in northeastern Iran. The company-produced sepiolite has passed through the 325 mesh sieve and has been acid-washed to remove impurities. Distilled water, isopropanol, methanol, vinyltriethoxysilane (VTES) as a modifier of sepiolite nanofibers, dioctyl phthalate (DOP) as a second phase, and ethanol as extractor without any additives were sourced from Ghatran Shimi Company. VTES and DOP are manufactured by Merck Company in Germany. The lithium hexaflourophosphate (LiPF6) electrolyte solution was dissolved in ethylene carbonate (EC), diethyl carbonate (DEC), and dimethyl carbonate (DMC) in a weight ratio of $1: 1: 1$, all of which were sourced directly from Sigma-Aldrich Company.

\subsection{Sepiolite nanofibers modification}

Sepiolite powder was first passed through a 500 mesh sieve. To purify the sepiolite powder, $10 \mathrm{~g} / 1$ of the sepiolite was mechanically stirred in distilled water for $24 \mathrm{~h}$. After $2 \mathrm{~min}$, the supernatant suspension was filtered, and the solid sample was dried at $105^{\circ} \mathrm{C}$ for $24 \mathrm{~h}$. The purified sepiolite was modified by VTES. The sepiolite ( $5 \mathrm{~g}$ ) was first dispersed in isopropanol $(400 \mathrm{ml})$, and mixed with a mechanical stirrer in a glass reactor, and then hydrolyzed VTES $(0.12 \mathrm{M})$ was added drop by drop at room temperature. The mixture was stirred at $60^{\circ} \mathrm{C}$ for $2 \mathrm{~h}$. The resulting mixture was filtered and then washed with methanol. The modified sepiolite was dried at $50^{\circ} \mathrm{C}$ in a vacuum oven for $24 \mathrm{~h}$, and sieved for subsequent use.

\subsection{Preparation of the HDPE/sepiolite nanocomposite separators}

HDPE/sepiolite microporous separators were fabricated through melt mixing followed by phase separation and extraction of the dispersed phase (TIPS).
Table 1. Sample designation information.

\begin{tabular}{|l|c|c|c|c|}
\hline $\begin{array}{c}\text { Sample } \\
\text { name }\end{array}$ & $\begin{array}{c}\text { HDPE } \\
{[\mathbf{w t} \%]}\end{array}$ & $\begin{array}{c}\text { Modified } \\
\text { sepiolite } \\
{[\mathbf{w t} \%]}\end{array}$ & $\begin{array}{c}\text { DOP } \\
\text { [wt\%] }\end{array}$ & $\begin{array}{c}\text { Purified } \\
\text { sepiolite } \\
{[\mathbf{w t} \%]}\end{array}$ \\
\hline PE & 40 & 0 & 60 & 0 \\
\hline PE-3PS & 40 & 0 & 57 & 3 \\
\hline PE-1MS & 40 & 1 & 59 & 0 \\
\hline PE-3MS & 40 & 3 & 57 & 0 \\
\hline PE-5MS & 40 & 5 & 55 & 0 \\
\hline
\end{tabular}

Before use, sepiolite and polyethylene powders were heated in a vacuum oven at a temperature of $80^{\circ} \mathrm{C}$ to remove moisture. Modified sepiolite (MS), HDPE, and DOP with certain percentages were poured simultaneously into the compartment of the internal mixer (Brabender PL2000). The samples codes and compositions are given in Table 1. The melt mixing was carried out at $180^{\circ} \mathrm{C}$ and $70 \mathrm{rpm}$ for $10 \mathrm{~min}$ to achieve a good dispersion of sepiolite nanofibers and DOP droplets in a polyethylene matrix. It should be mentioned that HDPE and DOP are thermodynamically immiscible pairs and phase-separated morphology is expected after their melt mixing. To form the film, the HDPE/MS/DOP melt mixed compound was placed between two mirror-polished stainless steel plates that were covered with two polyester films and an aluminum foil used as a mold. To obtain $50 \mu \mathrm{m}$ film, the sample was compressed under $20 \mathrm{MPa}$ pressure at $170^{\circ} \mathrm{C}$ for $10 \mathrm{~min}$. Subsequently, the stainless steel plate containing the membrane was detached and cooled at room temperature for $30 \mathrm{~min}$. The membrane was then immersed in ethanol for $24 \mathrm{~h}$ in order to extract the DOP phase and subsequently dried at $70^{\circ} \mathrm{C}$ temperature in the oven. The schematic of the steps for the preparation of the HDPE/sepiolite nanocomposite separator is shown in Figure 1.

\subsection{Characterizations}

To visually examine the sepiolite nanofibers, the fibrous shape of the sepiolite, the length of the sepiolite nanofibers, the pores of the HDPE/sepiolite membrane, images were taken from the surface and cross-section of the sample using FESEM (TeScanMira III model, Czech Republic). The separators were previously freeze-fractured in liquid nitrogen and sputter-coated with gold.

The FTIR, Spectrum RXI model, PerkinElmer, USA, in 4000 to $400 \mathrm{~cm}^{-1}$ wavenumbers was used in order to determine any physical and chemical bond between the components. 


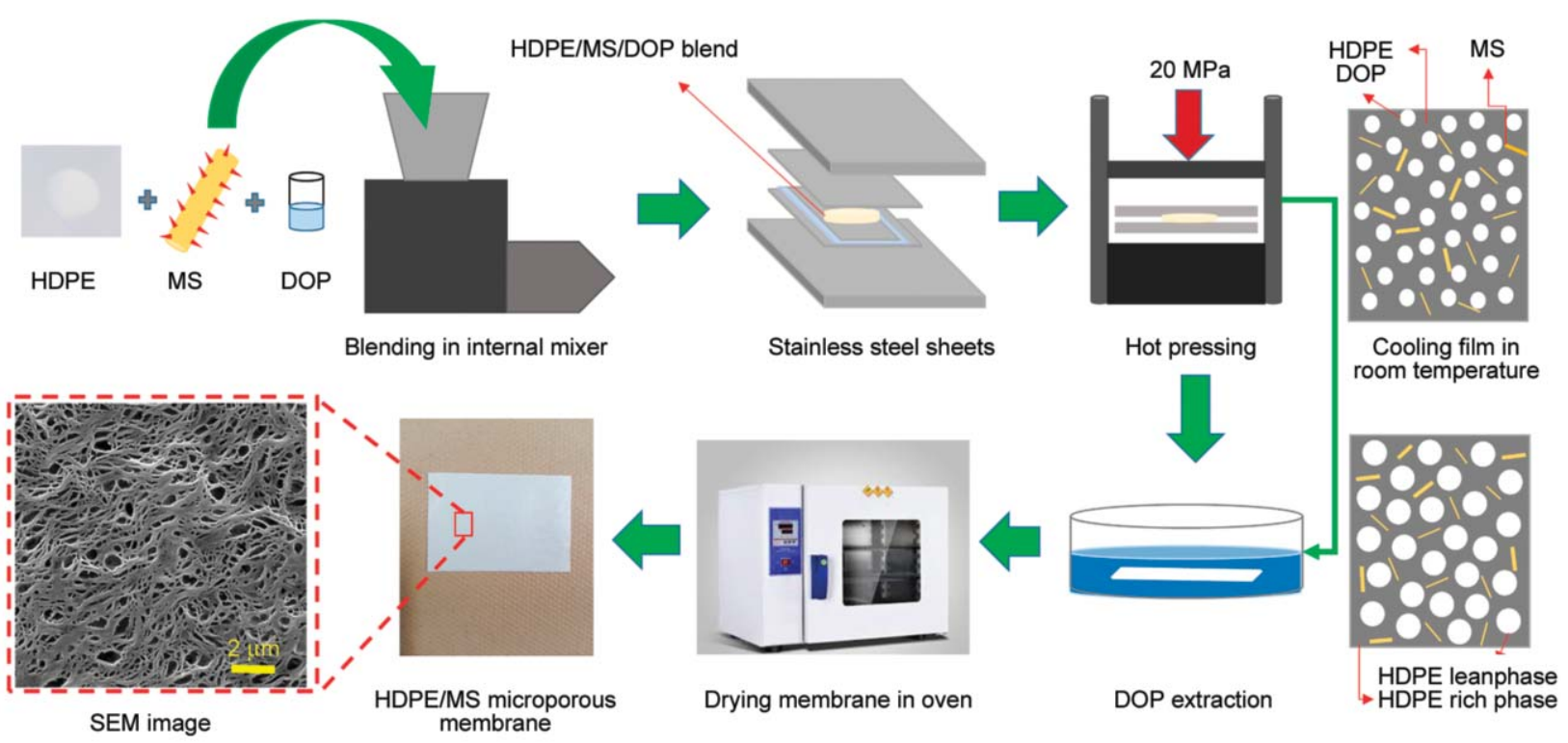

Figure 1. Schematic showing the preparation of the HDPE/Sepiolite nanocomposite separators.

The XRD (PANalytical Company X'Pert PRO MPD, Netherlands) was used to determine the characteristic peaks of the sepiolite and crystalline structure of samples in $2 \theta$ range of $2-70^{\circ}$.

Two methods were utilized to determine the effect of sepiolite nanofibers on the hydrophilicity and wettability of polyethylene separators: In the first method, the separator contact angle test using water droplet was used. The separator contact angle with distilled water $(4 \mu \mathrm{l})$ was measured using the sessile drop method at room temperature (OCA 15 plus, Dataphysics company). In the second method, to evaluate the absorption behavior of the electrolyte on the separator surface, about $25 \mu 1$ of electrolyte was poured on the surface of the samples and an image was taken immediately from the surface of the sample [52].

The tensile properties of the samples were evaluated according to ASTM D638 standard using Hounsfield H10KS model with a strain rate of $5 \mathrm{~mm} / \mathrm{min}$ and a $10 \mathrm{KN}$ barometer. An average of 5 measurements was reported.

The thermal analysis of the sample using non-isothermal Differential Scanning Calorimetry (DSC) test was evaluated by Q100 (model) device manufactured by TA Instruments. The samples were heated at a rate of $10^{\circ} \mathrm{C} / \mathrm{min}$ at a temperature range of 40-200 ${ }^{\circ} \mathrm{C}$ in an $\mathrm{N}_{2}$ atmosphere.

In order to measure the porosity, prepared separators were immersed in ethanol for $24 \mathrm{~h}$. In this method, samples with dimensions of $2 \times 2 \mathrm{~cm}^{2}$ were prepared. The weight of the samples was measured before and after immersed in ethanol. The porosity of the separators was obtained from Equation (1) [53]:

$P=\frac{\left(w_{0}-w\right) \rho_{\mathrm{h}}}{\rho_{\mathrm{h}} w_{0}+\left(\rho_{\mathrm{e}}-\rho_{\mathrm{h}}\right) w} \cdot 100 \%$

where $P$ indicates the porosity of the separator, $w$ is the total weight of the dry separator, $w_{0}$ is the weight of the wet separator, $\rho_{\mathrm{e}}$ represents the density of the ethanol, and $\rho_{\mathrm{h}}$ indicates the density of the HDPE.

To measure the electrolyte uptake of the separator, the weight of the separator was measured before and after floating it for 24 hours in the electrolyte solution (1 M LiPF 6 in EC/DEC/DMC 1:1:1). The electrolyte uptake $(A \%)$ of the prepared separators was obtained from Equation (2) [54]:

$A \%=\frac{W_{2}-W_{1}}{W_{1}} \cdot 100 \%$

where $W_{2}$ is the weight of the separator after floating in the electrolyte solution, and $W_{1}$ is the weight of the separator before floating in the electrolyte solution.

The thermal shrinkage of the separator was determined by measuring the change in sample dimensions after storing it at $150^{\circ} \mathrm{C}$ for $30 \mathrm{~min}$. For this purpose, samples were prepared in the dimensions of $3 \times 3 \mathrm{~cm}$ and then kept in the oven for $30 \mathrm{~min}$. The percentage of thermal shrinkage is obtained from Equation (3) [55]:

Shrinkage $[\%]=\frac{A_{2}-A_{1}}{A_{1}} \cdot 100 \%$ 
where $A_{2}$ is the area of the separator after being placed in the oven and $A_{1}$ before being placed in the oven.

\subsection{Electrochemical measurements}

The electrochemical performance of the separator was investigated by 2032 coin-type half-cells. In which the separator was placed between the lithium metal anode and the cathode of lithium iron phosphate $\left(\mathrm{LiFePO}_{4}\right)\left(\mathrm{LiFePO}_{4} /\right.$ Acetylene black/PVDF $=80 / 10 / 10)$, and soaked with the liquid electrolyte (1 $\mathrm{M} \mathrm{LiPF}_{6}$ in EC/DEC/DMC 1:1:1). The tests were performed on a battery cycle tester (Neware BTS3000 ) at a voltage range of $2.5-4.2 \mathrm{~V}$. The resistance of the interface and the stability of the separator with the electrodes were evaluated. Charge-discharge cycling tests were performed for 50 cycles at a current density of $0.2 \mathrm{C}$. C-rate capability measurements were conducted at current rates of $0.2-2 \mathrm{C}$.

The electrochemical stability window of the separators was determined by performing linear sweep voltammetry (LSV) at $5 \mathrm{mV} \cdot \mathrm{s}^{-1}$ over a voltage range 3.0-6.0 Vvs. $\mathrm{Li}^{+} / \mathrm{Li}$. The separator was tested using stainless steel and Li foil as the respective working and counter electrodes. The ionic conductivity of the separator was measured by electrochemical impedance spectroscopy (EIS). The coin-type test cells were assembled by placing the separator between two stainless steel electrodes and soaked with the electrolyte solution (1 $\mathrm{M} \mathrm{LiPF}_{6}$ in $\mathrm{EC} / \mathrm{DEC} / \mathrm{DMC}$ $1: 1: 1)$ to measure the $\mathrm{AC}$ impedance. Impedance data were obtained in the frequency range of $10 \mathrm{~Hz}-$ $100 \mathrm{kHz}$ with an amplitude of $10 \mathrm{mV}$ at room temperature. The ionic conductivity was obtained from Equation (4) [40]:

$\rho=\frac{d}{R \cdot A}$

where $d$ is the thickness of the separator, $A$ is the surface area of the lithium electrode, and $R$ is the electrolyte resistance measured by the $\mathrm{AC}$ impedance.

\section{Results and discussion}

\subsection{Characterization of modified sepiolite}

Figure 2 shows the FESEM images of the Sepiolite nanofibers. Figures $2 \mathrm{a}$ and $2 \mathrm{~b}$ show purified nanofibers, and Figures $2 \mathrm{c}$ and $2 \mathrm{~d}$ show modified nanofibers using VTES. The needle-like and fibrous structure of the sepiolite is vividly seen in the images, and unlike the platelet clays, sepiolite has a linear structure. Sepiolite nanofibers are between 100 nanometers and 2 micrometers long and range in diameter from 20 nanometers to 100 nanometers. Figures $2 \mathrm{a}$ and $2 \mathrm{~b}$ show a large number of intertwined sepiolite nanofibers. Sepiolite nanofibers are usually aggregated into bundles due to surface bonds. Prior to modification, the sepiolite nanofibers have a smooth surface and are joined together by surface bonds to form agglomerates. After modifying the sepiolite with VTES, the surface of the nanofibers becomes coarse and rough due to the formation of an uneven VTES layer, the surface bonds weaken, and the nanofibers become spaced apart, as shown in Figure 2c and 2d.

Figure 3 a shows the FTIR spectrum of purified and modified sepiolite nanofibers. The medium-intensity band in the range of $3700-3300 \mathrm{~cm}^{-1}$ is related to the symmetric and asymmetric stretching of $\mathrm{O}-\mathrm{H}$, and also its bending vibration band observed in the range of $800-650$ and $1650 \mathrm{~cm}^{-1}$, which indicates the existence of different types of water in the structure of sepiolite nanofibers [42]. The stretching vibration of 1230,1020 , and $970 \mathrm{~cm}^{-1}$ and the bending vibration of $450 \mathrm{~cm}^{-1}$ are related to the $\mathrm{Si}-\mathrm{O}$ group. The band associated with $\mathrm{Si}-\mathrm{O}-\mathrm{Mg}$ group is observed at $430 \mathrm{~cm}^{-1}$. In general, the absorption bands seen in the range of $1300-400 \mathrm{~cm}^{-1}$ are specific bands of silicate minerals that are mostly related to the bond between oxygen and silicon groups in the tetrahedral layer as well as oscillations of oxygenmagnesium groups in octahedral mineral planes [48]. The VTES-modified nanofibers show all bands related to purified sepiolite. Moreover, we also see a new symmetric and asymmetric stretching vibration attributed to the $\mathrm{C}-\mathrm{H}_{2}$ groups at $2970,2880 \mathrm{~cm}^{-1}$, and a bending vibration at $1390 \mathrm{~cm}^{-1}$, which confirms the reaction of sepiolite nanofibers with VTES. Figure $3 \mathrm{~b}$ shows the results of the X-ray diffraction test for purified and modified sepiolite nanofibers. As mentioned earlier, sepiolite is a crystalline silicate with a strong characteristic peak at $2 \theta=7.1^{\circ}$, which is also clear in Figure 3b, and shows that the crystal structure of the sepiolite is mostly formed by crystalline plane of (110). The next characteristic peak of the sepiolite has appeared at $2 \theta=26.67^{\circ}$, and the next one has appeared at $2 \theta=7.6^{\circ}$. In addition to the characteristic sepiolite peaks in the diffraction pattern, two intensive peaks are seen at $2 \theta=31$ and $41^{\circ}$, which is the sub-phase and is related to the dolomite mineral [56]. The diffraction pattern and characteristic peaks related to VTES-modified sepiolite are similar to those of unmodified sepiolite so that even 


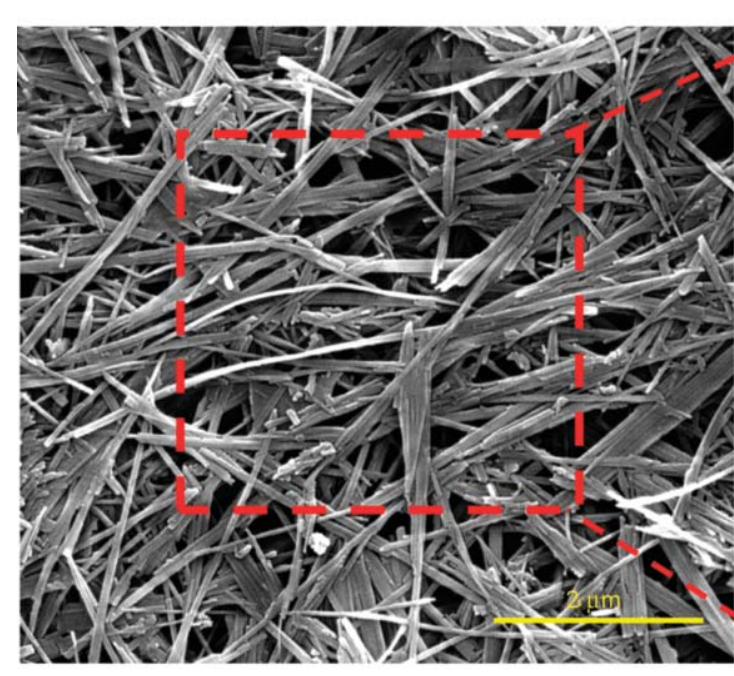

a)

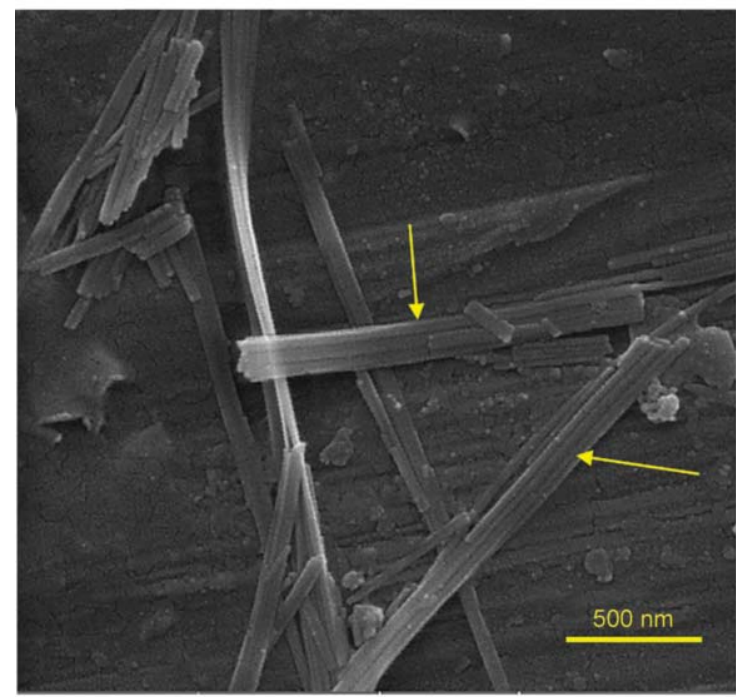

c)

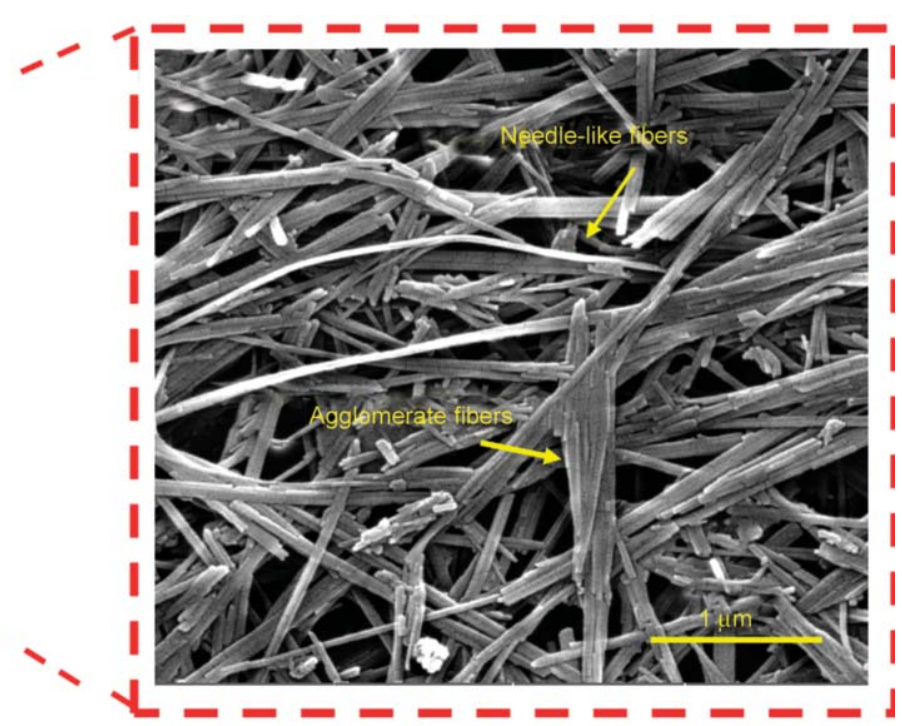

b)

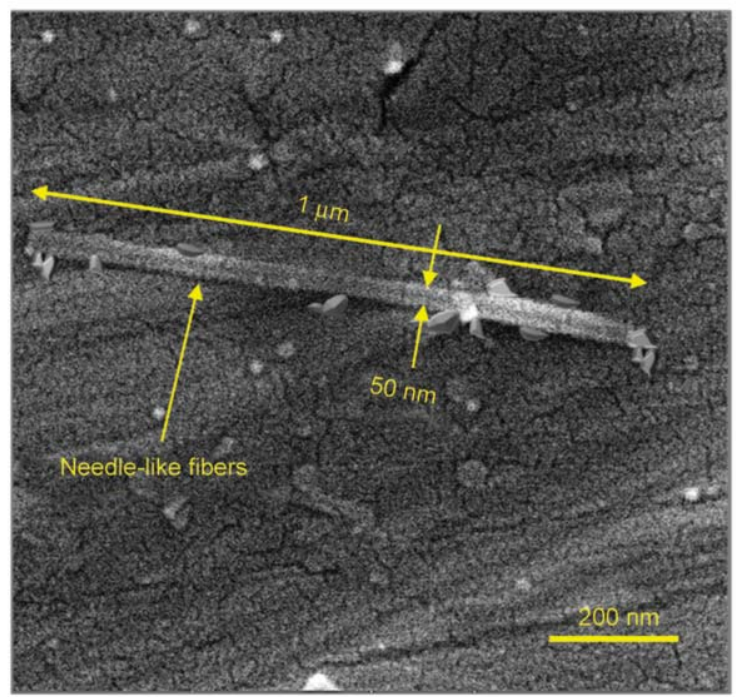

d)

Figure 2. FE-SEM micrographs of (a, b) purified and (c, d) modified sepiolite nanofibers.

the distance between the crystalline planes remains unchanged. Table 2 illustrates the results of the XRD test data. As shown in Table 2, the $d$-spacing of the modified and unmodified sepiolite structures is approximately equal. This indicates that during the modification of sepiolite by VTES, only the surface hydroxyl $(\mathrm{O}-\mathrm{H})$ groups of the sepiolite react with the silanol $(\mathrm{Si}-\mathrm{O})$ group of VTES, and the main structure of the sepiolite remains unchanged. Based on the FTIR and XRD results, the schematic of the modified sepiolite (MS) nanofibers is shown in Figure 4. The silanol groups of vinyl triethoxy silane (VTES) react with the hydroxyl groups of sepiolite, and its vinyl moiety reacts with the polymer matrix.

\subsection{Morphology and surface properties of HDPE/sepiolite nanocomposite separators}

Figure 5 demonstrates the FE-SEM surface images of the separators. The porous structure is a key feature

Table 2. XRD results of the purified and modified sepiolite.

\begin{tabular}{|c|c|c|c|c|c|}
\hline Peak number & Crystallinity plane & $\begin{array}{c}\text { Peak angle, 20 } \\
{\left[{ }^{\circ} \text { ] }\right.}\end{array}$ & $\begin{array}{c}\boldsymbol{d} \text {-spacing of purified sepiolite } \\
{[\mathbf{n m}]}\end{array}$ & $\begin{array}{c}\boldsymbol{d} \text {-spacing of modified sepiolite } \\
{[\mathbf{n m}]}\end{array}$ & $\begin{array}{c}\text { Intensity, } \\
\boldsymbol{I} / \mathbf{I}_{\mathbf{0}}\end{array}$ \\
\hline 1 & $(110)$ & 7.10 & 1.21 & 1.22 & 78.43 \\
\hline 2 & $(261)$ & 26.67 & 0.37 & 0.38 & 27.40 \\
\hline 3 & $(040)$ & 7.60 & 1.06 & 1.07 & 3.77 \\
\hline
\end{tabular}



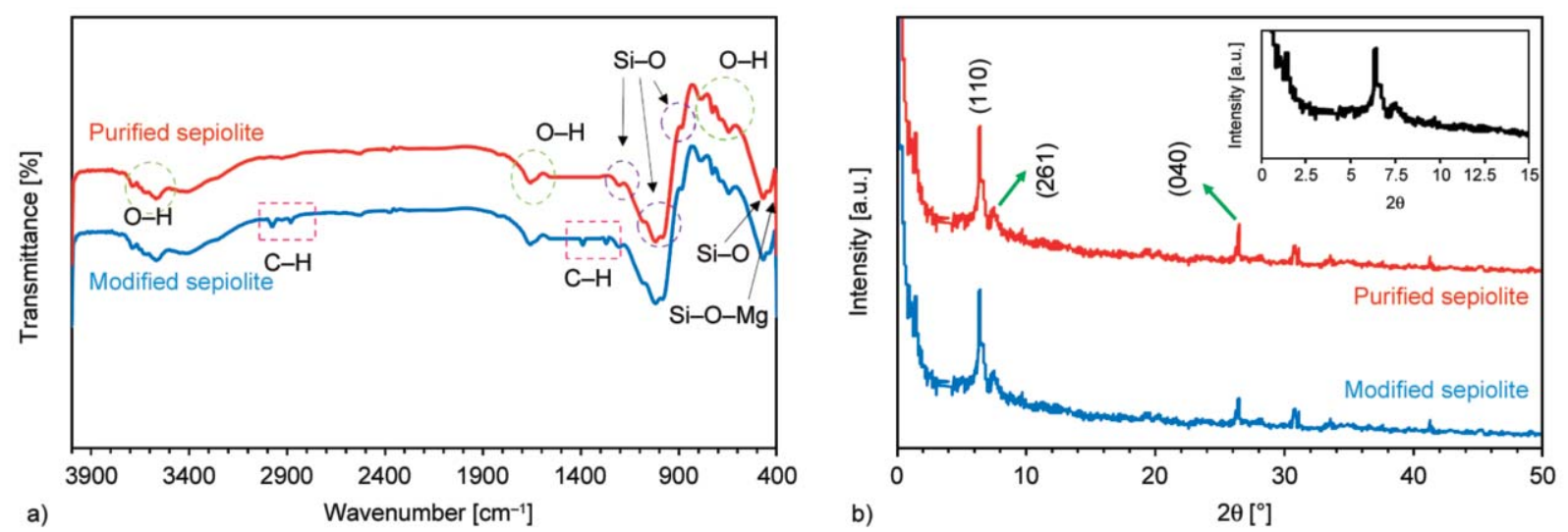

Figure 3. (a) FTIR spectra and (b) XRD patterns of the purified and modified sepiolite nanofibers.

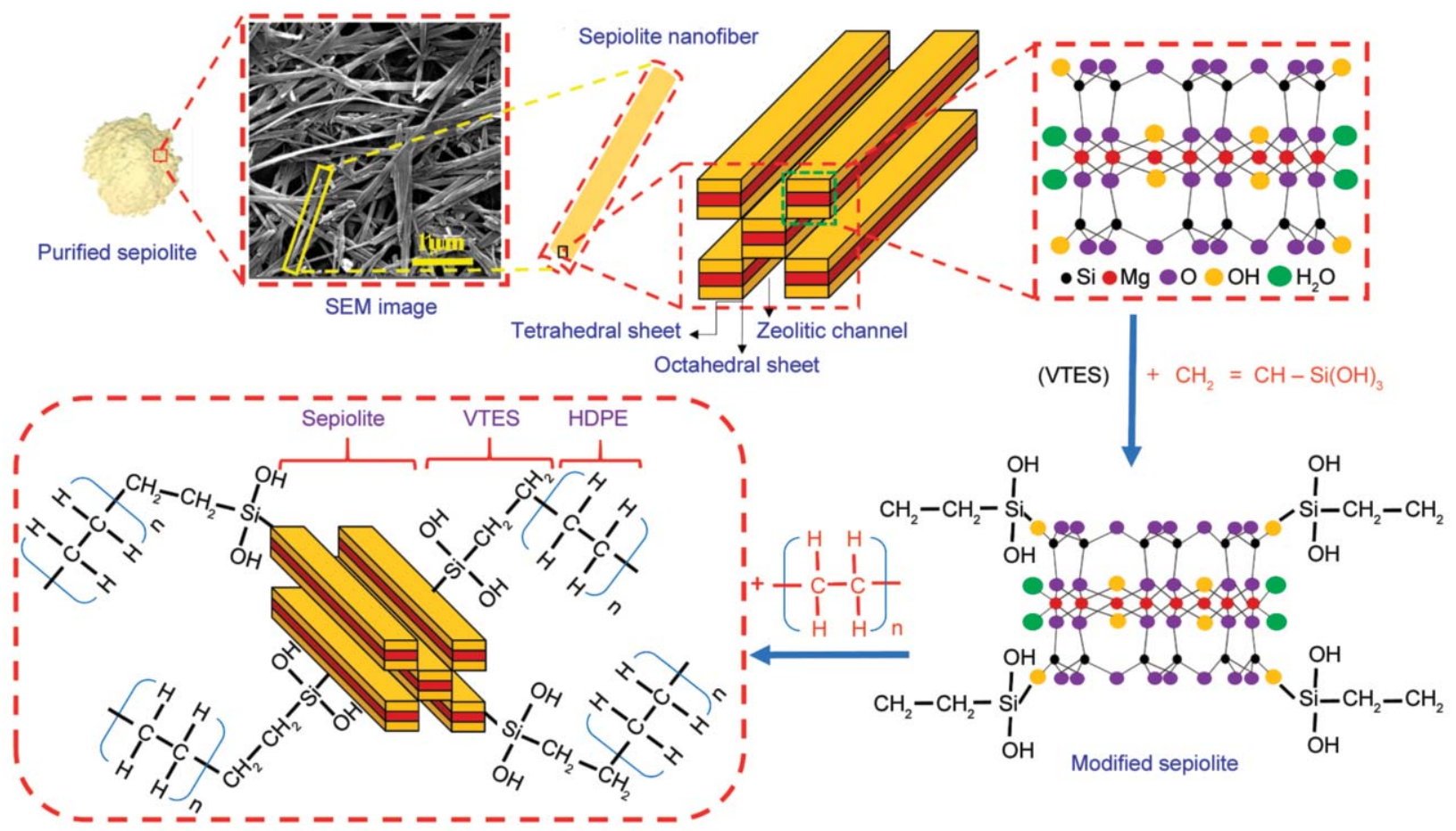

Figure 4. Schematic illustration of modification of the Sepiolite nanofibers.

in the separators of lithium-ion batteries [57]. As it is clear in all Figures, the separators have porous surfaces, and the pores are approximately ellipsoidal in shape. Because TIPS-manufactured membranes usually have large porosity sizes that may not be suitable for use as a separator, thus the PE-3MS sample has a more suitable porosity size. In this sample, as shown in Figure $5 \mathrm{~g}$ and $5 \mathrm{~h}$, the average size of the pores is less than $500 \mathrm{~nm}$. Pores being small in size and uniformly distributed are suitable for inhibiting the diffusion of particles from the cathode to the anode in the separator and on the suppression of lithium dendritic [57]. As a result, the size of the pores being in the sub-micron range can help ionic conduction balance and electrical insulation in the separator. There are almost no aggregates in
HDPE/1MS and HDPE/3MS separators. The sepiolite nanofibers are uniformly dispersed, mainly because of suppressing the interactions between sepiolite nanofibers and enhancing the interaction between sepiolite and HDPE matrix via the formation of physical interactions and entanglements between VTES molecules and HDPE chains. Dispersion and distribution of nano-filler in the polymer mass play a vital role in the physical and mechanical properties of obtained nanocomposites. In the image related to HDPE/5MS separator, Figure $5 \mathrm{i}$ and $5 \mathrm{j}$, it can be seen that the sepiolite nanofibers accumulate on the pores and create a dense, almost nonporous surface. The agglomeration of nanofibers at higher concentrations is usually seen in polymer nanocomposites [45]. 


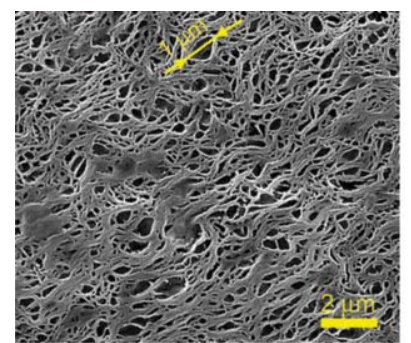

a)

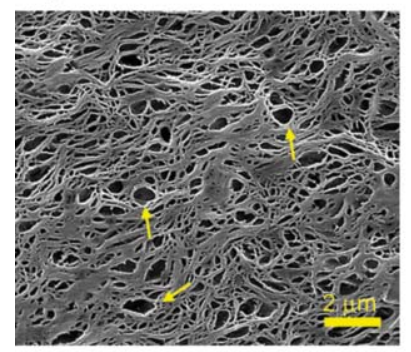

e)

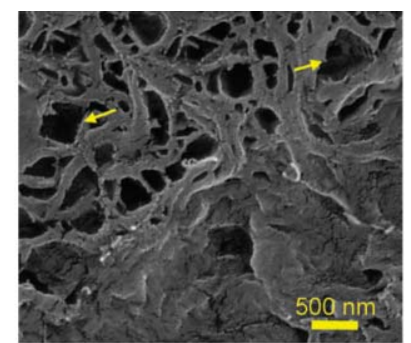

b)

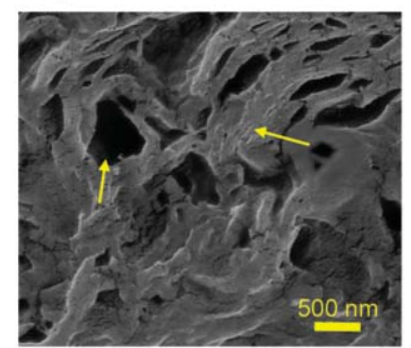

f)

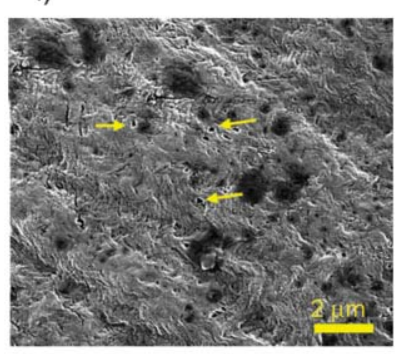

i)

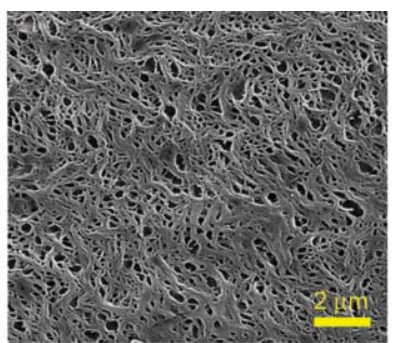

c)

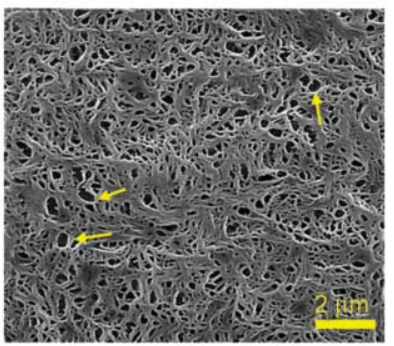

g)

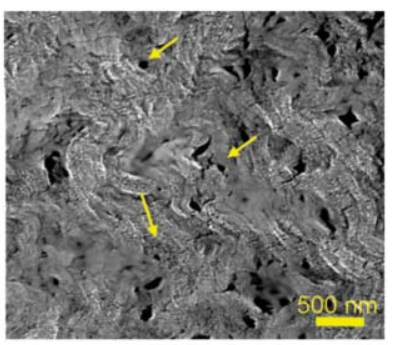

j)

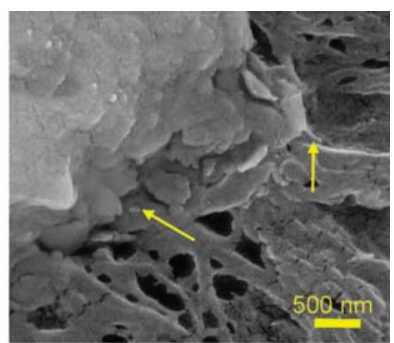

d)

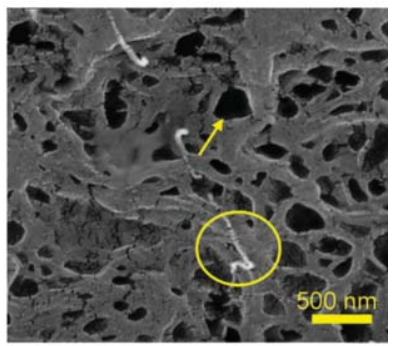

h)

Figure 5. (a-j) FE-SEM Surface micrographs of the pure HDPE (a and b), PE-3PS (c and d), PE-1MS (e and f), PE-3MS (g and $h$ ), and PE-5MS ( $i$ and j) separators in two magnifications.

Figure 6 shows the FE-SEM cross-section images of the separators. According to the TIPS method and its mechanism, because the DOP phase and HDPE are immiscible blends with phase-separated morphology after DOP phase extraction, the cell porous structure having interconnected pores is formed, as shown in Figure 6. This means that porous structure is formed in both the presence and absence of sepiolite nanofibers; however, sepiolite nanofibers affect the size and shape of the pores. With the increase of sepiolite concentration, they will distribute in both of DOP and HDPE phases, and the viscosity will increase, resulting in the change in the morphology of HDPE/ DOP blend and final structure of the separators. During the DOP extraction, the sepiolites in the DOP phase will remain and agglomerated and fill the formed pores; as a result, the porosity decreases (Table 3), so does the size of the pores, as shown in Figure $6 \mathrm{i}$ and $6 \mathrm{j}$ and Figure $5 \mathrm{i}$ and $5 \mathrm{j}$ by adding more sepiolite, the porosity is more reduced, so that in the PE-5MS sample minimum porosity and pores size were obtained.

The FTIR spectra for pure HDPE and HDPE/sepiolite nanocomposite separators are shown in Figure 7a.
The characteristic HDPE bands associated with $\mathrm{C}-\mathrm{H}$ stretching vibration are observed at $2960,2870 \mathrm{~cm}^{-1}$. Bending vibration related to $\left(-\mathrm{CH}_{2}\right)$ group has appeared in 1460 and $720 \mathrm{~cm}^{-1}$. The FTIR spectrum related to the nanocomposite shows the combination of HDPE and sepiolite bands. The appearance of the $\mathrm{Si}-\mathrm{O}$ bands in the range of $1100-1000 \mathrm{~cm}^{-1}$ and the $\mathrm{O}-\mathrm{H}$ band in the $3600-3400 \mathrm{~cm}^{-1}$ range confirms the addition of sepiolite to the HDPE matrix. Furthermore, the intensity of the sepiolite characteristic peaks increases with sepiolite concentration. Moreover, the absence of new peaks indicates that no chemical reaction has occurred between polyethylene chains and sepiolite modifiers.

Figure $7 \mathrm{~b}$ shows the XRD pattern for pure HDPE and the HDPE/sepiolite nanocomposite. As illustrated, the polyethylene characteristic peaks are well visible in all diagrams pointing out the semi-crystalline structure of HDPE. The characteristic and strong peak corresponding to the (110) crystalline plane of polyethylene has appeared at $2 \theta=21.62^{\circ}$. The next characteristic peak of polyethylene is at $2 \theta=24.03^{\circ}$ and corresponds to the crystal plane (220) of polyethylene [42]. The third peak, which 


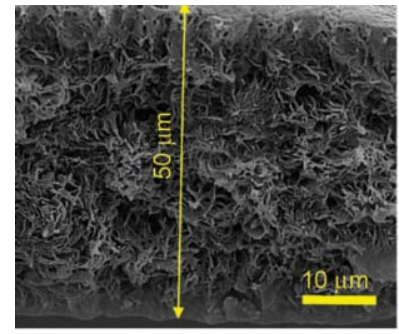

a)

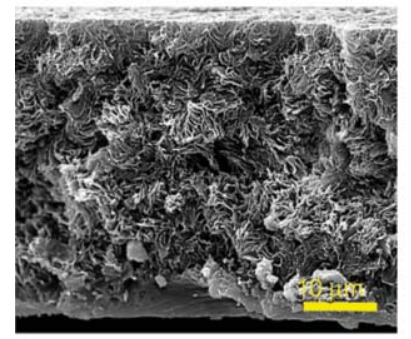

e)

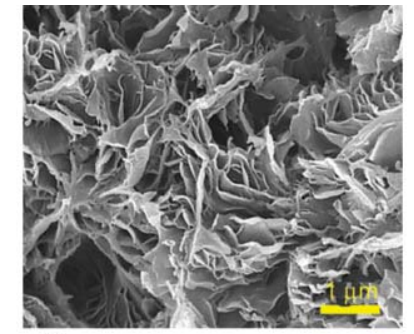

b)

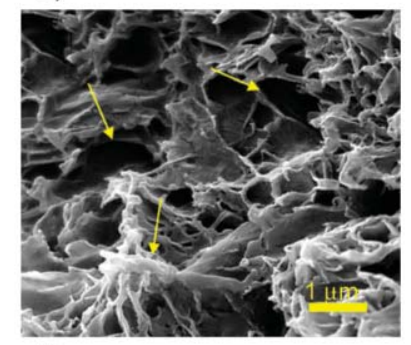

f)

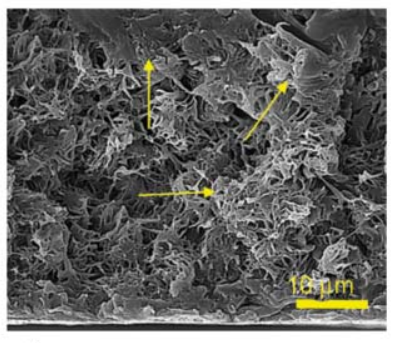

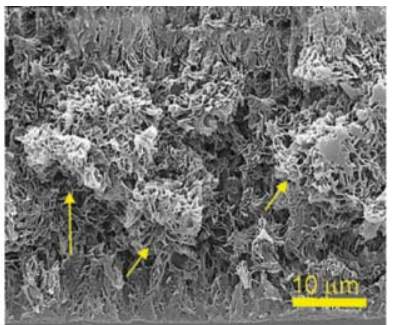

c)

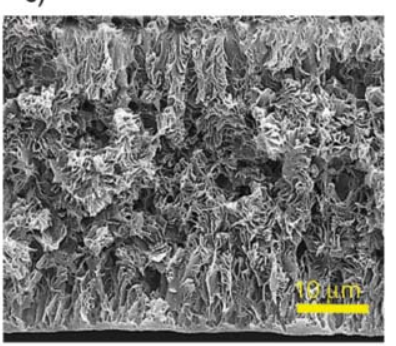

g)

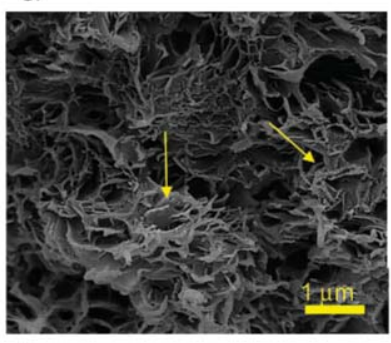

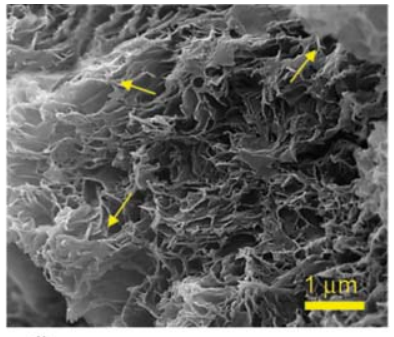

d)

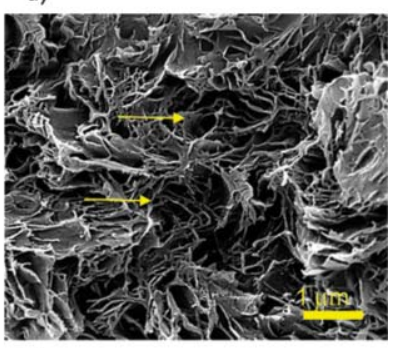

h)

j)

Figure 6. FE-SEM cross-section micrographs of the pure HDPE (a and b), PE-3PS (c and d), PE-1MS (e and f), PE-3MS (g and $\mathrm{h}$ ), and PE-5MS (i and j) separators in different magnification.

has a low intensity, corresponds to the plate (020) of polyethylene and appears at $2 \theta=36.32^{\circ}$, which decreased with the increase of sepiolite content. So, in general, three characteristic peaks of polyethylene appear in the diagram; all three peaks are belonging to polyethylene orthorhombic unit cell structure [50]. A strong characteristic peak of sepiolite has appeared in the nanocomposite spectrum with lower intensity at $2 \theta=7.21$ and $26^{\circ}$. The reason for their low intensity is low concentration relative to the matrix (semicrystalline polyethylene). It is worth mentioning that the intensity of PE-3MS is higher than PE-3PS, which shows good dispersion of sepiolite in PE-3MS. However, the higher concentration of the sepiolite, the higher intensity at $7.21^{\circ}$ is observed, in agreement with FTIR results.

Figure 8a shows the contact angle of the separators with the water. As can be seen in figure, the contact angle of the membrane made of pure polyethylene is $118^{\circ}$, while by adding sepiolite nanofibers, the contact angle has been significantly decreased. This is due to the following reasons: (1) the porous structure of the sepiolite nanofibers and (2) the hydrophilicity of the nanofibers, which is attributed to the presence
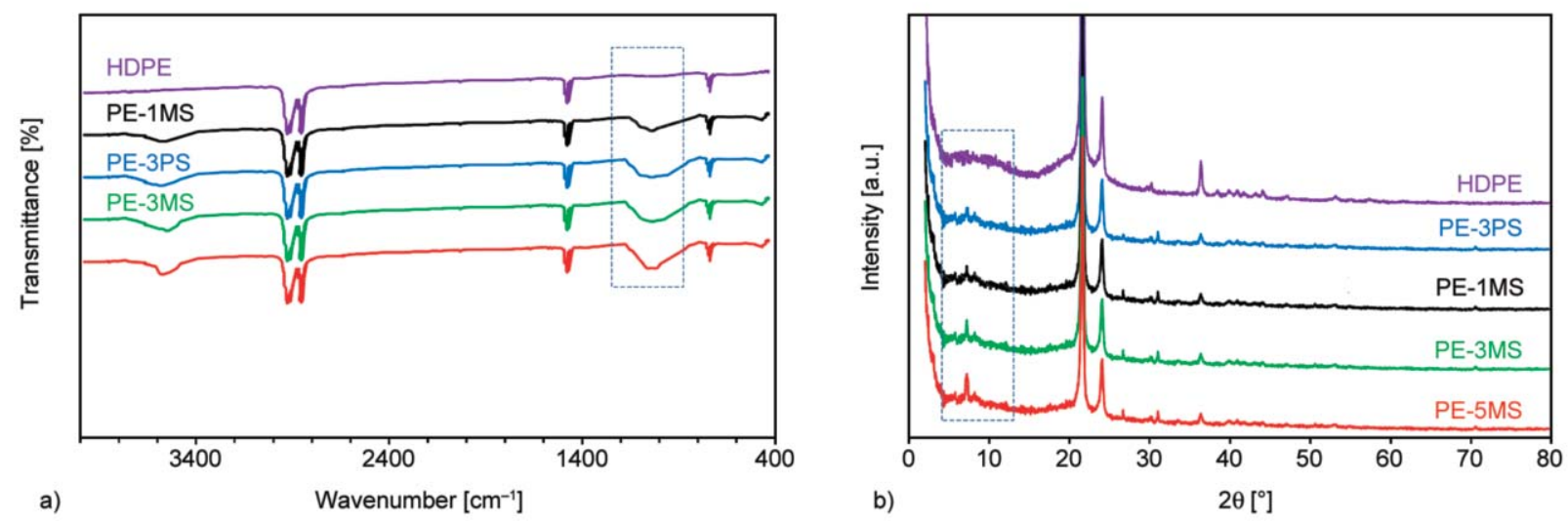

Figure 7. (a) FTIR spectra and (b) XRD patterns of the pure HDPE, and nanocomposite separators samples. 
Table 3. Mechanical and thermal properties of the pure HDPE and nanocomposite separator samples.

\begin{tabular}{|l|c|c|c|c|c|}
\hline Sample name & $\begin{array}{c}\text { Yield strength } \\
{[\mathbf{M P a}]}\end{array}$ & $\begin{array}{c}\text { Elongation at break } \\
{[\mathbf{\%}]}\end{array}$ & $\begin{array}{c}\text { Melting temperature } \\
{\left[{ }^{\circ} \mathbf{C}\right]}\end{array}$ & $\begin{array}{c}\text { Crystallization temperature } \\
{\left[{ }^{\circ} \mathbf{C}\right]}\end{array}$ & $\begin{array}{c}\text { Crystallinity content } \\
{[\%]}\end{array}$ \\
\hline HDPE & 1.3 & 41 & 127.2 & 113.7 & 70 \\
\hline PE-3PS & 3.9 & 12 & 127.5 & 112.7 & 62 \\
\hline PE-1MS & 5.6 & 38 & 128.1 & 112.4 & 60 \\
\hline PE-3MS & 7.3 & 30 & 130.0 & 111.3 & 55 \\
\hline PE-5MS & 6.5 & 20 & 128.5 & 112.1 & 58 \\
\hline
\end{tabular}

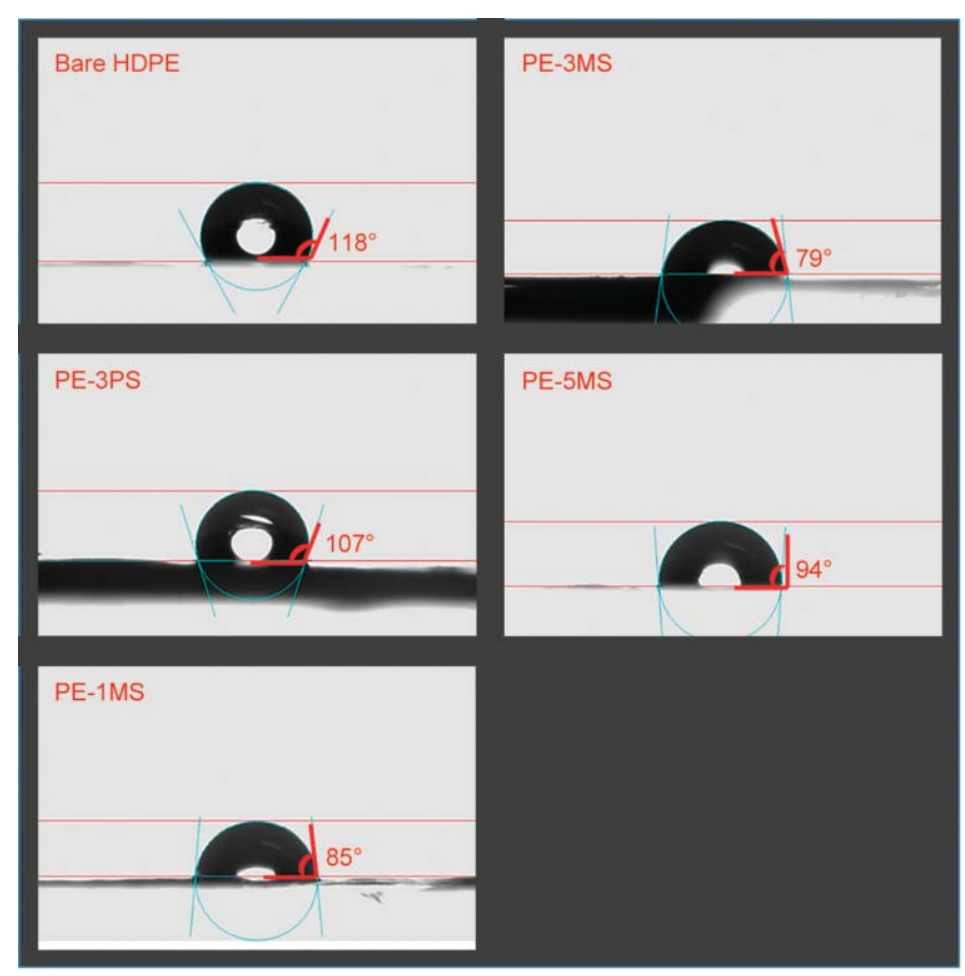

a)

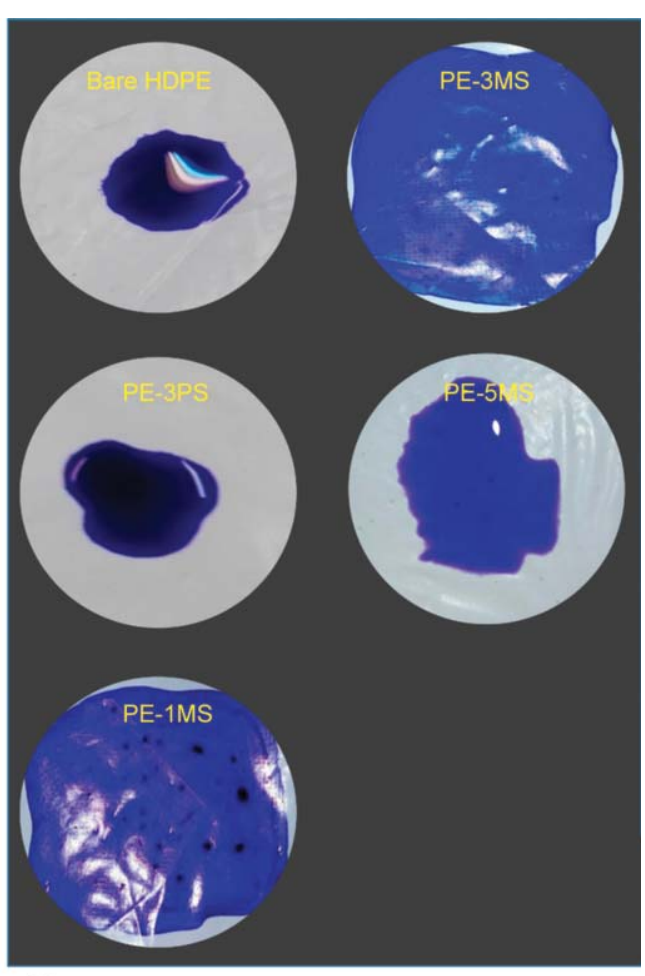

b)

Figure 8. Photographs of (a) the water contact angles and (b) the liquid electrolyte wetting behavior of the pure HDPE, and nanocomposite separator samples.

of $\mathrm{OH}$ groups on them [36]. Among all the samples, the PE-3MS has the lowest contact angle of $79^{\circ}$, which is due to the better dispersion of the sepiolite nanofiber and its proper amount in this weight percentage. Also, comparing the contact angle of PE3MS and PE-3PS samples, the critical role of sepiolite modification with VTES is highlighted.

Figure $8 \mathrm{~b}$ shows the wettability behavior of the separators with the electrolyte solution. As can be seen, in terms of wettability, samples containing sepiolite nanofibers are significantly more effective in the electrolyte solution than pure polyethylene samples. It has been observed that for the PE-1MS and PE-3MS separators, the electrolyte solution is completely dispersed on the separator surface, indicating improvement in wettability and hydrophilicity of the separator with sepiolite nanofibers. Interestingly, the comparison of PE-3MS and PE-3PS qualitatively confirmed the better dispersion and interaction of modified sepiolite with polyethylene chains and in good agreement with other results. In the PE-5MS sample, because of the high concentration of sepiolite and its agglomeration, the contact angle is increased, and wettability decreased compared with the PE-3MS samples, as shown in Figure 8.

\subsection{Thermal and mechanical properties}

Mechanical properties are one of the most important features of the separator that are essential to maintain its stability in the battery during the manufacturing process and during the transportation and movement of the battery [23]. Figure 9a shows the stress-strain diagram of the separator with different percentages of sepiolite nanofibers. We see a clear increasing trend in yield strength and modulus, as the slope of stressstrain curves in low strains, of the samples with the addition of sepiolite nanofibers, so that the mechanical strength of PE-5MS and PE-3MS samples shows 

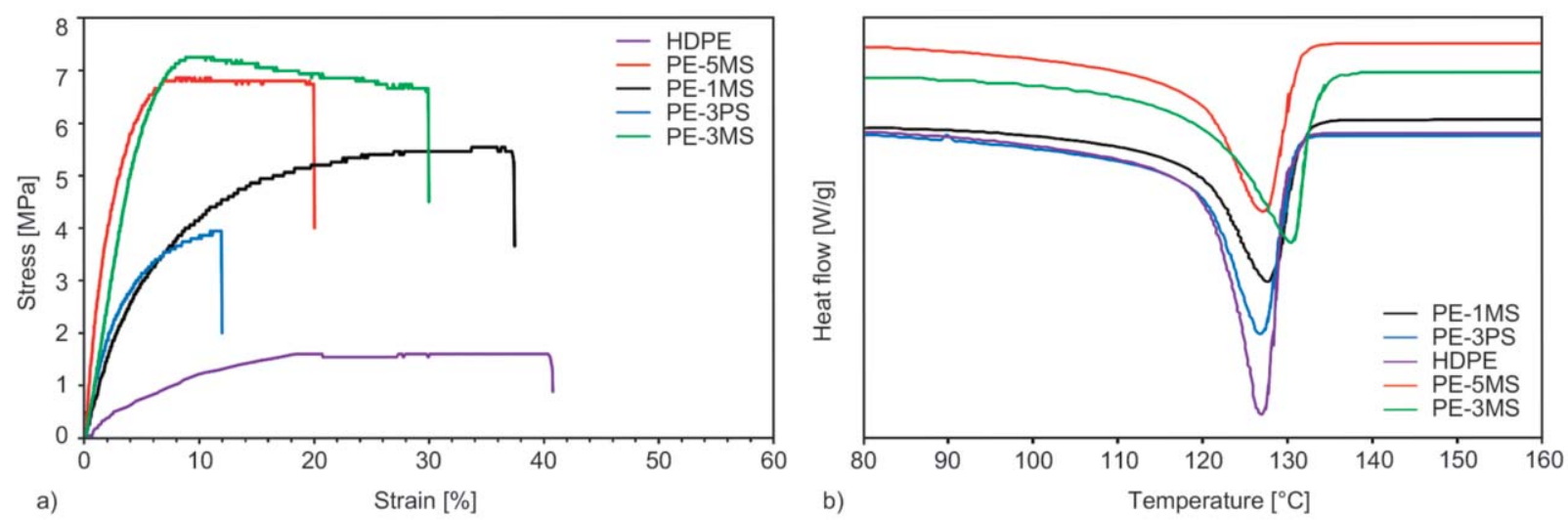

Figure 9. (a) Stress-strain and (b) DSC curves of the pure HDPE, and nanocomposite separators.

a significant increase compared to other samples. The yield stress, tensile modulus, and elongation at break are calculated in Table 3. The PE-3MS sample has the highest yield strength (approximately $7.3 \mathrm{MPa}$ ) and toughness (estimated as the area below the stress-strain curve), which is due to the following reasons: (1) sepiolite nanofibers act as a hard phase in the polyethylene, and (2) the dispersion of nanofibers occurs well [44]. Also, because the sepiolite nanofibers are physically bonded with polyethylene by VTES, the transfer of stress from the matrix to the nanofiber is well carried out. All of these reasons combined have led to such high mechanical properties. The PE-3PS sample shows a yield strength of 3.9 $\mathrm{MPa}$, which is less than the sample with modified sepiolite, and the reason for this is that due to the lack of sepiolite modification, firstly, the sepiolite nanofibers are not well dispersed, and secondly, due to the weak bond of the material with the nanofiber, the transfer of stress from the matrix to the nanofiber is rarely occurring [58]. Therefore, the elongation at break for this sample is the lowest. Considering the higher sensitivity of tensile modulus to the filler concentration rather than the dispersion [58], the highest tensile modulus in the PE-5MS sample is due to its highest sepiolite concentration.

Figure $9 \mathrm{~b}$ shows the heating cycle diagram for different samples. As can be seen in the figure, the melting temperature of the samples has changed significantly. The melting temperature, crystallization temperature, and crystallinity content are presented in Table 3. The melting temperature of the PE-3MS sample is approximately $130^{\circ} \mathrm{C}$, which is 2.8 degrees higher than the melting temperature of the pure HDPE sample. This suggests that the interaction of the sepiolite nanofibers to the HDPE chains is well done, which increases the thermal stability of the separator. The melting temperature of the PE-3PS sample is approximately equal to that of pure HDPE, pointing to less interaction between unmodified sepiolites and polymer matrix than expected.

Figure 10 illustrates the dimensional changes of the separators after being placed in an oven with a temperature of $150^{\circ} \mathrm{C}$ for $30 \mathrm{~min}$. Pure HDPE separator has the highest thermal shrinkage of $92 \%$, and the PE-3MS sample has the lowest thermal shrinkage of $5 \%$ at $150{ }^{\circ} \mathrm{C}$, show its highest dimensional stability at higher temperatures. The high thermal stability and low shrinkage of the PE-3MS sample are attributed to the fact that the sepiolite nanofibers as the mineral filler with high thermal stability are uniformly dispersed in the polyethylene. The PE-1MS sample shows a $45 \%$ thermal shrinkage, and the reason is that although the sepiolite nanofibers are uniformly dispersed in the sample, their amount in the matrix has been low. The PE-5MS sample also shows $8 \%$ shrinkage due to partial agglomeration of

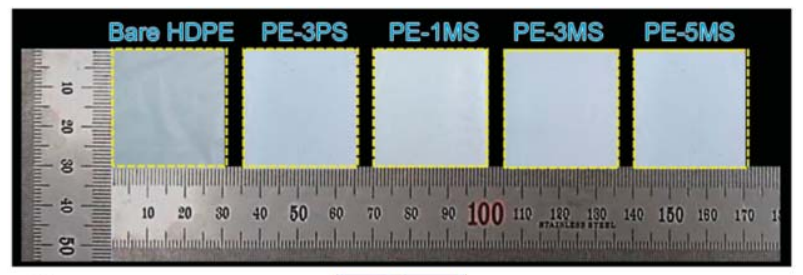

a)

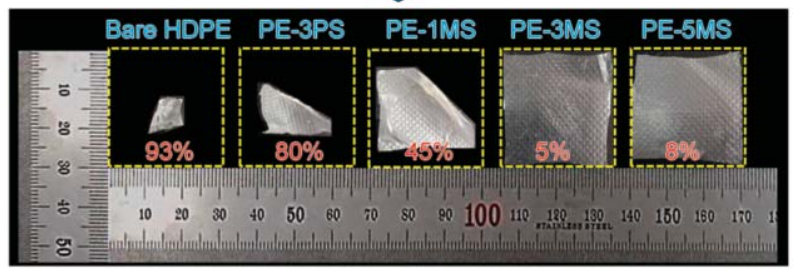

b)

Figure 10. Photographs of the pure HDPE and nanocomposite separators (a) before and (b) after storage at $150{ }^{\circ} \mathrm{C}$ for $0.5 \mathrm{~h}$. 
the sepiolite nanofibers. These results clearly demonstrate the key role of the sepiolite nanofibers as mineral filler on the thermal behavior of separators which is crucial for battery performance at elevated temperatures [59].

\subsection{Electrochemical measurements}

The electrochemical stability window of the bare HDPE and HDPE/sepiolite nanocomposite separators were investigated by a linear sweep voltammetry experiment, as shown in Figure 11a. The current changes only slightly in voltages lower than $4.5 \mathrm{~V}$ (vs. $\mathrm{Li}^{+} / \mathrm{Li}$ ), indicating that HDPE/sepiolite nanocomposite microporous membranes can be used in lithium-ion batteries. The ionic conductivity of the separator is one of the main parameters in the electrochemical performance of the battery. The Electrochemical impedance spectroscopy (EIS) was used to measure the ionic conductivity of pure HDPE separator and HDPE/sepiolite nanocomposite (Figure 11b, 11c). According to Equation (4), the ionic conductivity of the pure HDPE separator and PE$3 \mathrm{MS}$ was measured to be $0.36 \cdot 10^{-3}$ and $0.9 \cdot 10^{-3} \mathrm{~S} \cdot \mathrm{cm}^{-1}$, respectively. Table 4 shows the ionic conductivity of the separators, along with the porosity and electrolyte uptake. The high ionic conductivity of the PE-3MS separator is originated from its high wettability and uniform porous structure, which provides a smooth ion diffusion path. In addition, it is expected that the addition of sepiolite into the polymer matrix enhances the amorphous region; and the increase of the amorphous region in the polymer complex is beneficial for achieving a higher ionic conductivity of the electrolyte system [60]. It is worth mentioning that the decrease in porosity of the samples is low, while the highest value is observed in PE-5MS sample is also expected based on FE-SEM images in Figure 5i and 5j.

The compatibility of the electrodes and the separator with interfacial resistance was also measured by the EIS method. Figure 11b shows the Nyquist plots of lithium/separator $/ \mathrm{LiFePO}_{4}$ cells in open circuit
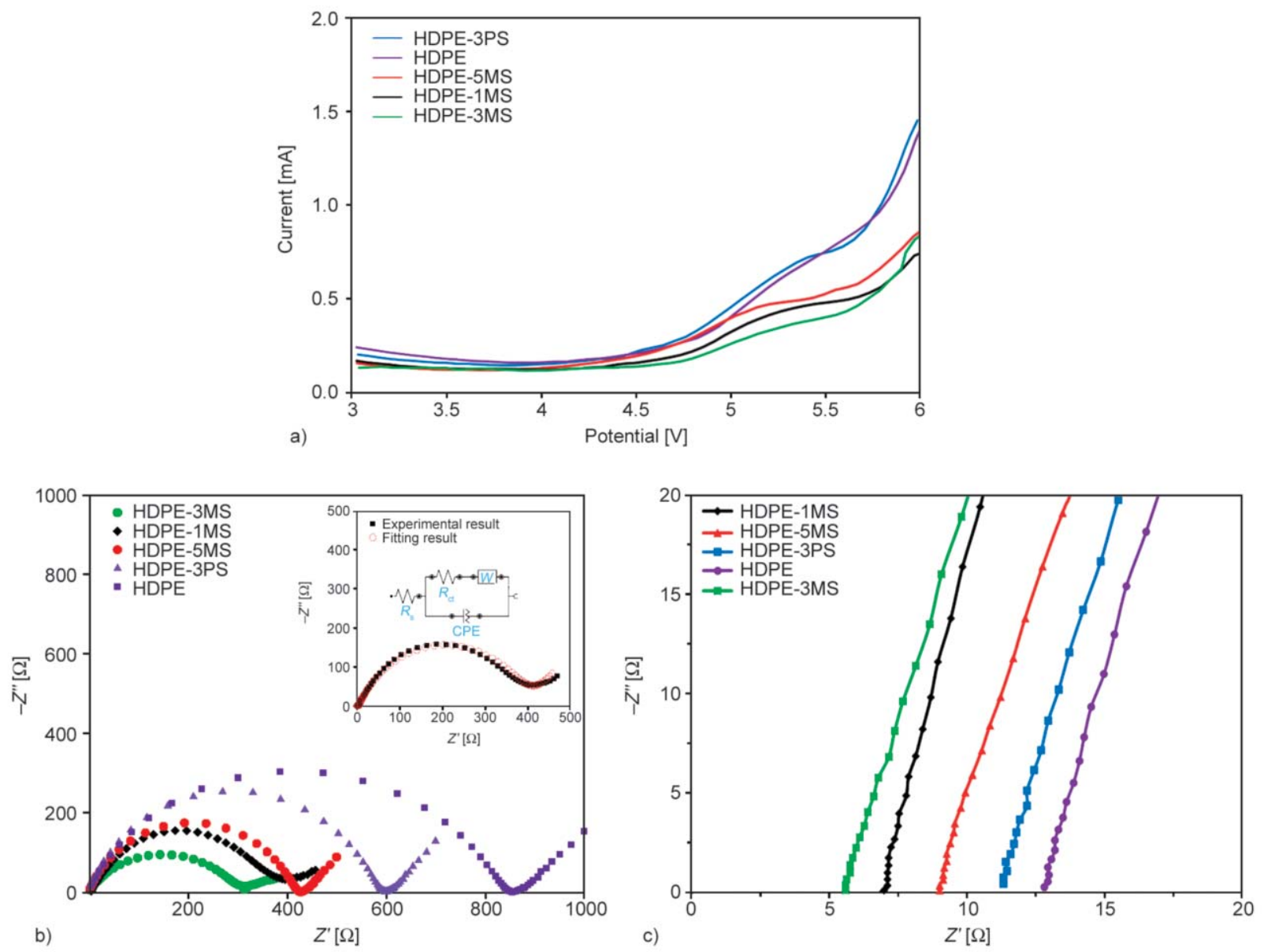

Figure 11. (a) Linear sweep voltammograms of pure HDPE and nanocomposite separators and (b) Nyquist plots of the $\mathrm{Li} / \mathrm{HDPE} / \mathrm{LiFePO}_{4}$, the Li/HDPE-PS/LiFePO , and the $\mathrm{Li} / \mathrm{HDPE}-\mathrm{MS} / \mathrm{LiFePO}_{4}$ cells at the open circuit potential and equivalent circle (inset), and (c) the ionic conductivity of the pure HDPE, and nanocomposite separators. 
Table 4. The porosity, electrolyte uptake and ionic conductivity of the pure HDPE, and nanocomposite separator samples.

\begin{tabular}{|l|c|c|c|c|}
\hline $\begin{array}{c}\text { Sample } \\
\text { name }\end{array}$ & $\begin{array}{c}\text { Porosity } \\
{[\mathbf{\%}]}\end{array}$ & $\begin{array}{c}\text { Electrolyte } \\
\text { uptake } \\
{[\mathbf{\%}]}\end{array}$ & $\begin{array}{c}\text { Ion } \\
\text { conductivity } \\
{\left[\cdot \mathbf{1 0}^{-\mathbf{3}} \mathbf{S} \cdot \mathbf{c m}^{-\mathbf{1}}\right]}\end{array}$ & $\begin{array}{c}\boldsymbol{R}_{\mathrm{ct}} \\
{[\mathbf{\Omega}]}\end{array}$ \\
\hline Bare PE & 60 & 84 & 0.36 & 850 \\
\hline PE-3PS & 59 & 90 & 0.41 & 588 \\
\hline PE-1MS & 59 & 110 & 0.73 & 387 \\
\hline PE-3MS & 58 & 120 & 0.90 & 310 \\
\hline PE-5MS & 55 & 102 & 0.56 & 416 \\
\hline
\end{tabular}

potential. The first intercept in the high-frequency region on the real axis shows the electrolyte solution resistance $\left(R_{\mathrm{S}}\right)$. The diameter of the semicircle represents the overall interfacial resistance $\left(R_{\text {int }}\right)$, which takes into account the resistance of the charge transfer $\left(R_{\mathrm{ct}}\right)$ through the interface and that one associated with the interfacial passivation layer (solid electrolyte interface (SEI) layer) growing on the lithium surface [61-64]. As it is clear from the diagram, the interfacial resistance decreases with the addition of
Sepiolite nanofibers. The equivalent circuit is depicted in Figure $11 \mathrm{~b}$ inset. As can be seen, the fitting result coincides with the experimental one. As shown in Table 4, the cell containing PE-3MS separator has the lowest resistance value ( $320 \Omega$ ) compared to the HDPE separator sample that has the highest resistance value $(850 \Omega)$. This indicates an increase in the ion exchange rate between the separator and the electrodes. This is because by adding sepiolite nanofibers, the separator is swollen more by liquid electrolyte and provides strong adhesion of the interfaces with the electrodes, which leads to less use of the resistance layer in the battery.

Figure 12a shows the initial charge-discharge curves of $\mathrm{Li} / \mathrm{LiFePO}_{4}$ half-cells at $0.2 \mathrm{C}$ by using the pure HDPE and HDPE/sepiolite nanocomposite separators. Compared to the electrode with a bare PE separator, the $\mathrm{LiFePO}_{4}$ electrodes with the HDPE/sepiolite nanocomposite separators have a slightly higher initial reversible capacity, which can be attributed to the higher ionic conductivity and lower interfacial
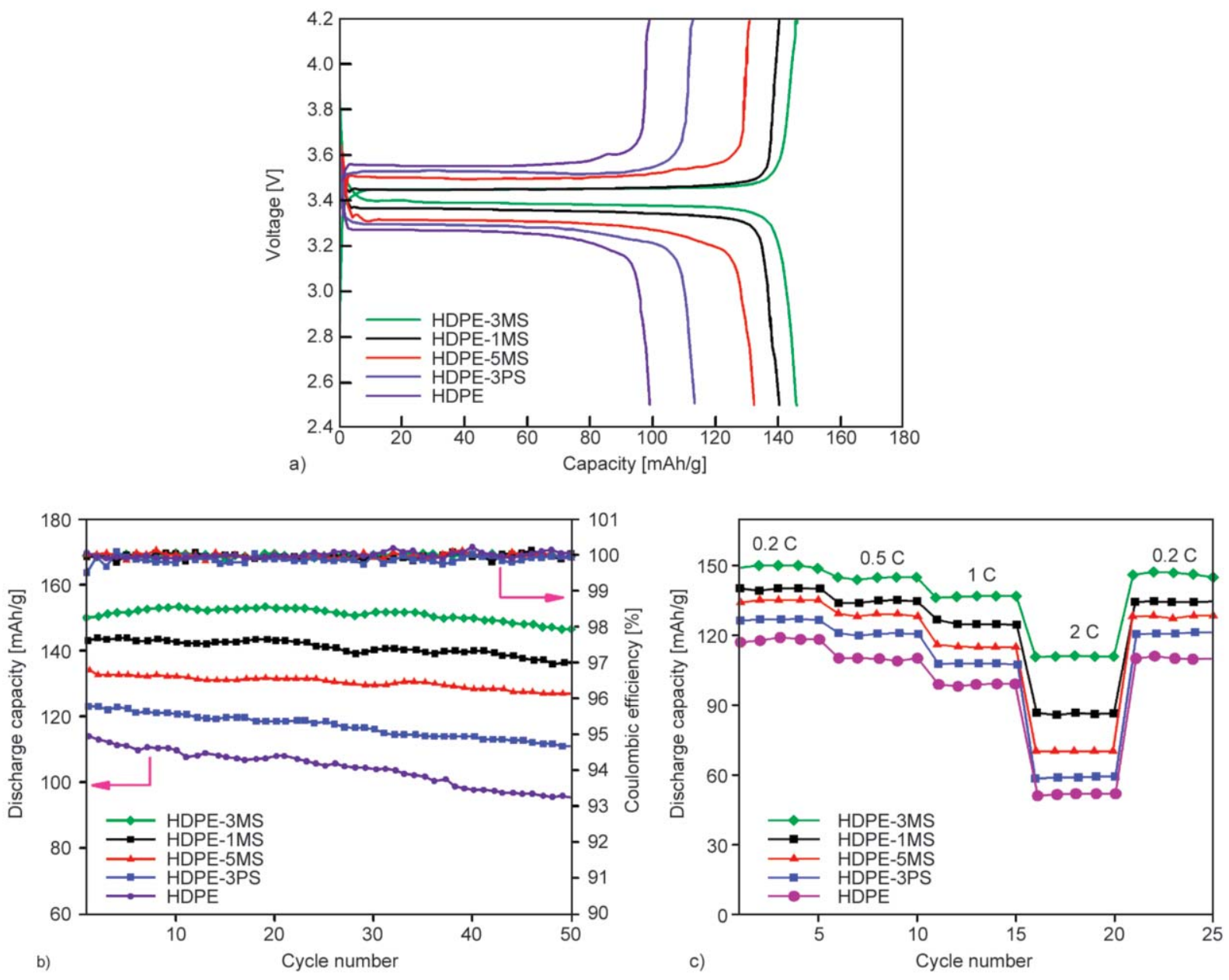

Figure 12. (a) Charge-discharge curves at the rate of $0.2 \mathrm{C}$, (b) the cycling performances and (c) the rate performances of the pure HDPE and nanocomposite separators samples. 
impedance [65]. The resulting polarization value $(0.07 \mathrm{~V})$ between the charge and discharge plateaus of HDPE-3MS is considerably lower than those of the HDPE $(0.24 \mathrm{~V})$, HDPE-1MS $(0.09 \mathrm{~V})$, HDPE5MS $(0.19 \mathrm{~V})$, and HDPE-1PS $(0.23 \mathrm{~V})$. This low polarization value $(0.07 \mathrm{~V})$ is indicative of the enhanced ionic conductivity (Figure 12a) and lower the electrochemical impedance of the HDPE-3MS nanocomposite separator interface (Figure 11b).

Cycling performance is used to evaluate the stability of the battery. Figure 12b shows the change in capacity retention with the cell cycle numbers for different separators at a current density of $0.2 \mathrm{C}$. All separators show stable performance with a slight degradation of performance after 50 cycles. As can be seen, the discharge capacity of the battery increases with the addition of sepiolite nanofibers to the separator, and the differences between the capacities increase with an increasing number of cycles. This difference is explained by the high affinity of the liquid electrolyte and the high ionic conductivity of the separators due to the addition of sepiolite nanofibers, which sufficiently wet the electrode material, increasing the intercalation and de-intercalation of lithium ions on the cathode, resulting in high discharge capacity. In addition, the cellular and microporous structure of the separator can contribute to the sealing of the electrolyte over a long period of time and result in better reversibility [57]. The Coulombic efficiency (CE) diagram during the first 50 cycles for bare HDPE and different HDPE/sepiolite nanocomposite samples is shown in Figure 12b. CEs of approximately close to $100 \%$ is observed for all samples during the 100 cycles at the discharge current rate of $\mathrm{C} / 2$, regarding good reversibility and stability during charge-discharge cycling.

Rate performance is also an important parameter in lithium-ion batteries. Figure 12c compares separators' behavior with increasing C-rate from 0.2 to $2 \mathrm{C}$ for all five cycles. It is observed that the cell with PE3MS separator shows a higher discharge capacity at different discharge $\mathrm{C}$-rates, which results in high cathode utilization and high discharge C-rate capability. This improved capacity rate is attributed to high porosity and electrolyte uptake, which is suitable for facile $\mathrm{Li}^{+}$transport and good electrolyte uptake during cycling. The difference between the separators in the high current density is greater where the effect of ionic transfer on ohmic polarization is extremely essential. For all separators, the discharge capacity of

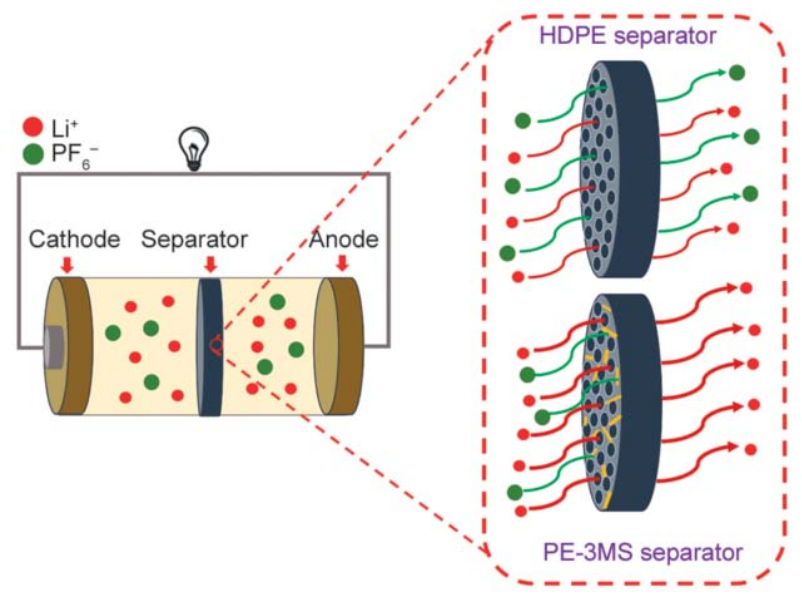

Figure 13. Schematic illustration the ionic conductivity of the pure HDPE and the PE-3MSseparators.

the cells gradually decreases as the discharge current density increases [66]. When the C-rate drops to $0.2 \mathrm{C}$, the capacity of the cells containing different separators is restored to the initial value, which is a requirement for lithium batteries. In general, the ability to discharge essentially depends on the transfer of ions. Figure 13 shows the schematic of cell charge-discharge in the presence and absence of sepiolite nanofibers. As can be seen, the presence of sepiolite nanofibers has increased ionic conductivity. In a pure HDPE separator, the $\mathrm{PF}_{6}{ }^{-}$ion hind the movement of $\mathrm{Li}^{+}$ion, while in the PE-3MS separator hydroxyl group in sepiolite forms a hydrogen bond with $\mathrm{PF}_{6}{ }^{-}$to improve the movement of $\mathrm{Li}^{+}$.

\section{Conclusions}

In this study, a new HDPE/sepiolite nanocomposite separator was prepared and characterized for use in lithium-ion batteries by utilizing the thermally induced phase separation method (TIPS). The addition of sepiolite nanofibers improved the thermal stability, hydrophilicity, and wettability of the separator. FESEM test results showed porous separators with a cellular structure that have ellipsoidal pores. It was also observed that the sample containing $3 \mathrm{wt} \%$ of VTES modified sepiolite has the best dispersion of nanofibers and has a uniform porous structure with a suitable porosity size. The FTIR test results showed that the sepiolite nanofibers were well modified with VTES and compatible with the polyethylene matrix due to the presence of the $\mathrm{C}-\mathrm{H}$ absorption band. The results of tensile, DSC, and thermal shrinkage tests showed the excellent effect of sepiolite nanofibers on mechanical properties enhancement and thermal stability, so that yield strength of PE-3MS sample 
is almost 5.5 times higher than pure polyethylene sample, and the melting point of PE-3MS is about $2.8^{\circ} \mathrm{C}$ higher than that of pure HDPE. Moreover, the PE-3MS sample had only $5 \%$ shrinkage and dimensional change after remaining at $150^{\circ} \mathrm{C}$ for $30 \mathrm{~min}$. The results of contact angle, electrolyte uptake, and ion conductivity tests showed that sepiolite nanofibers caused hydrophilicity in polyethylene, resulting in increased wettability and electrolyte uptake of separators. Also, the separator ionic conductivity increased from $0.36 \cdot 10^{-3} \mathrm{~S} \cdot \mathrm{cm}^{-1}$ for pure HDPE sample to $0.9 \cdot 10^{-3} \mathrm{~S} \cdot \mathrm{cm}^{-1}$, which indicates a decrease in the resistance of the separator interface with the electrodes. Cycling and rate performance test results showed that the cell assembled with PE3MS separator has a higher discharge capacity in the number of high cycles than the cell assembled with pure HDPE separator. Results of this work pave the way for the production of nanocomposite separators with higher efficiency and workability at higher temperatures using low-cost mineral nanofibers.

\section{References}

[1] Cheng Q., He W., Zhang X., Li M., Song X.: Recent advances in composite membranes modified with inorganic nanoparticles for high-performance lithium ion batteries. RSC Advances, 6, 10250-10265 (2016). https://doi.org/10.1039/C5RA21670B

[2] Costa C. M., Lee Y-H., Kim J-H., Lee S-Y., LancerosMéndez S.: Recent advances on separator membranes for lithium-ion battery applications: From porous membranes to solid electrolytes. Energy Storage Materials, 22, 346-375 (2019). https://doi.org/10.1016/j.ensm.2019.07.024

[3] Heidari A. A., Mahdavi H.: Recent development of polyolefin-based microporous separators for $\mathrm{Li}$-ion batteries: A review. The Chemical Record, 20, 570-595 (2020).

https://doi.org/10.1002/tcr.201900054

[4] Scrosati B., Garche J.: Lithium batteries: Status, prospects and future. Journal of Power Sources, 195, 2419-2430 (2010).

https://doi.org/10.1016/j.jpowsour.2009.11.048

[5] Sarı A., Sharma R. K., Hekimoğlu G., Tyagi V. V.: Preparation, characterization, thermal energy storage properties and temperature control performance of form-stabilized sepiolite based composite phase change materials. Energy and Buildings, 188, 111-119 (2019). https://doi.org/10.1016/j.enbuild.2019.02.008

[6] Na W., Lee A. S., Lee J. H., Hwang S. S., Kim E., Hong S. M., Koo C. M.: Lithium dendrite suppression with UV-curable polysilsesquioxane separator binders. ACS Applied Materials and Interfaces, 8, 12852-12858 (2016). https://doi.org/10.1021/acsami.6b02735
[7] Xu W., Wang Z., Shi L., Ma Y., Yuan S., Sun L., Zhao Y., Zhang M., Zhu J.: Layer-by-layer deposition of organic-inorganic hybrid multilayer on microporous polyethylene separator to enhance the electrochemical performance of lithium-ion battery. ACS Applied Materials and Interfaces, 7, 20678-20686 (2015).

https://doi.org/10.1021/acsami.5b05457

[8] Chen Q., Zhu R., Liu S., Wu D., Fu H., Zhu J., He H.: Self-templating synthesis of silicon nanorods from natural sepiolite for high-performance lithium-ion battery anodes. Journal of Materials Chemistry A, 6, 63566362 (2018).

https://doi.org/10.1039/C8TA00587G

[9] Jiang W., Jiang Y., Zhao S., Peng J., Qin W., Ouyang D., Ding Y.: Novel sepiolite-based materials for lithium- and sodium-ion storage. Energy Technology, 8, 1901262/11901262/7 (2020). https://doi.org/10.1002/ente.201901262

[10] Zhang H., Zhou M-Y., Lin C-E., Zhu B-K.: Progress in polymeric separators for lithium ion batteries. RSC Advances, 5, 89848-89860 (2015).

https://doi.org/10.1039/C5RA14087K

[11] Mirabad H. M., Nemati A., Faghihi-Sani M. A., Hasanabadi M. F., Abdoli H.: Effect of YSZ sol-gel coating on interaction of Crofer22 APU with sealing glass for solid oxide fuel/electrolysis cell. Journal of Alloys and Compounds, 847, 156496/1-156496/13 (2020).

https://doi.org/10.1016/j.jallcom.2020.156496

[12] Xiang Y., Li J., Lei J., Liu D., Xie Z., Qu D., Li K., Deng T., Tang H.: Advanced separators for lithium-ion and lithium-sulfur batteries: A review of recent progress. ChemSusChem, 9, 3023-3039 (2016). https://doi.org/10.1002/cssc.201600943

[13] Kim J. Y., Lim D. Y.: Surface-modified membrane as a separator for lithium-ion polymer battery. Energies, 3, 866-885 (2010). https://doi.org/10.3390/en3040866

[14] Yang M., Hou J.: Membranes in lithium ion batteries. Membranes, 2, 367-383 (2012). https://doi.org/10.3390/membranes2030367

[15] Huang X.: Separator technologies for lithium-ion batteries. Journal of Solid State Electrochemistry, 15, 649662 (2011). https://doi.org/10.1007/s10008-010-1264-9

[16] Wang Z., Guo F., Chen C., Shi L., Yuan S., Sun L., Zhu J.: Self-assembly of $\mathrm{PEI} / \mathrm{SiO}_{2}$ on polyethylene separators for Li-ion batteries with enhanced rate capability. ACS Applied Materials and Interfaces, 7, 3314-3322 (2015). https://doi.org/10.1021/am508149n

[17] Lagadec M. F., Zahn R., Wood V.: Characterization and performance evaluation of lithium-ion battery separators. Nature Energy, 4, 16-25 (2019). https://doi.org/10.1038/s41560-018-0295-9

[18] Zhang S. S.: A review on the separators of liquid electrolyte Li-ion batteries. Journal of Power Sources, 164, 351-364 (2007). https://doi.org/10.1016/j.jpowsour.2006.10.065 
[19] Terella A., De Giorgio F., Rahmanipour M., Malavolta L., Paolasini E., Fabiani D., Focarete M. L., Arbizzani C.: Functional separators for the batteries of the future. Journal of Power Sources, 449, 227556/1-227556/9 (2020).

https://doi.org/10.1016/j.jpowsour.2019.227556

[20] Martinez-Cisneros C., Antonelli C., Levenfeld B., Varez A., Sanchez J-Y.: Evaluation of polyolefin-based macroporous separators for high temperature Li-ion batteries. Electrochimica Acta, 216, 68-78 (2016).

https://doi.org/10.1016/j.electacta.2016.08.105

[21] Arora P., Zhang Z.: Battery separators. Chemical Reviews, 104, 4419-4462 (2004).

https://doi.org/10.1021/cr020738u

[22] Shi J-L., Fang L-F., Li H., Liang Z-Y., Zhu B-K., Zhu L-P.: Enhanced performance of modified HDPE separators generated from surface enrichment of polyether chains for lithium ion secondary battery. Journal of Membrane Science, 429, 355-363 (2013).

https://doi.org/10.1016/j.memsci.2012.11.055

[23] Liao H., Hong H., Zhang H., Li Z.: Preparation of hydrophilic polyethylene/methylcellulose blend microporous membranes for separator of lithium-ion batteries. Journal of Membrane Science, 498, 147-157 (2016). https://doi.org/10.1016/j.memsci.2015.09.064

[24] Shi J-L., Li H., Fang L-F., Liang Z-Y., Zhu B-K.: Improving the properties of HDPE based separators for lithium ion batteries by blending block with copolymer PE- $b$-PEG. Chinese Journal of Polymer Science, 31, 309-317 (2013).

https://doi.org/10.1007/s10118-013-1222-y

[25] Matsuyama H., Berghmans S., Lloyd D. R.: Formation of hydrophilic microporous membranes via thermally induced phase separation. Journal of Membrane Science, 142, 213-224 (1998). https://doi.org/10.1016/S0376-7388(97)00330-X

[26] Matsuyama H., Kim M-M., Lloyd D. R.: Effect of extraction and drying on the structure of microporous polyethylene membranes prepared via thermally induced phase separation. Journal of Membrane Science, 204, 413-419 (2002).

https://doi.org/10.1016/S0376-7388(02)00052-2

[27] Liu S., Zhou C., Yu W.: Phase separation and structure control in ultra-high molecular weight polyethylene microporous membrane. Journal of Membrane Science, 379, 268-278 (2011).

https://doi.org/10.1016/j.memsci.2011.05.073

[28] Park M. J., Kim C. K.: Fabrication of polyethylene microporous membranes using triethylolpropane tris(2ethylhexanoate) as a novel diluent by a thermally induced phase separation process. Journal of Membrane Science, 449, 127-135 (2014).

https://doi.org/10.1016/j.memsci.2013.08.004

[29] Razeghi M., Pircheraghi G.: TPU/graphene nanocomposites: Effect of graphene functionality on the morphology of separated hard domains in thermoplastic polyurethane. Polymer, 148, 169-180 (2018).

https://doi.org/10.1016/j.polymer.2018.06.026
[30] Cardoso V. F., Botelho G., Lanceros-Méndez S.: Nonsolvent induced phase separation preparation of poly (vinylidene fluoride-co-chlorotrifluoroethylene) membranes with tailored morphology, piezoelectric phase content and mechanical properties. Materials and Design, 88, 390-397 (2015).

https://doi.org/10.1016/j.matdes.2015.09.018

[31] Nunes-Pereira J., Costa C. M., Lanceros-Méndez S.: Polymer composites and blends for battery separators: State of the art, challenges and future trends. Journal of Power Sources, 281, 378-398 (2015). https://doi.org/10.1016/j.jpowsour.2015.02.010

[32] Li B., Li Y., Dai D., Chang K., Tang H., Chang Z., Wang C., Yuan X-Z., Wang H.: Facile and nonradiation pretreated membrane as a high conductive separator for Li-ion batteries. ACS Applied Materials and Interfaces, 7, 20184-20189 (2015). https://doi.org/10.1021/acsami.5b05718

[33] Rao E., McVerry B., Borenstein A., Anderson M., Jordan R. S., Kaner R. B.: Roll-to-roll functionalization of polyolefin separators for high-performance lithium-ion batteries. ACS Applied Energy Materials, 1, 3292-3300 (2018).

https://doi.org/10.1021/acsaem.8b00502

[34] Lee H., Yanilmaz M., Toprakci O., Fu K., Zhang X.: A review of recent developments in membrane separators for rechargeable lithium-ion batteries. Energy and Environmental Science, 7, 3857-3886 (2014). https://doi.org/10.1039/C4EE01432D

[35] Zhu X., Jiang X., Ai X., Yang H., Cao Y.: TiO 2 ceramic-grafted polyethylene separators for enhanced thermostability and electrochemical performance of lithium-ion batteries. Journal of Membrane Science, 504, 97-103 (2016). https://doi.org/10.1016/j.memsci.2015.12.059

[36] Yoo Y., Kim B. G., Pak K., Han S. J., Song H-S., Choi J. W., Im S. G.: Initiated chemical vapor deposition (iCVD) of highly cross-linked polymer films for advanced lithium-ion battery separators. ACS Applied Materials and Interfaces, 7, 18849-18855 (2015). https://doi.org/10.1021/acsami.5b05720

[37] Kim Y. B., Tran-Phu T., Kim M., Jung D-W., Yi G-R., Park J. H.: Facilitated ion diffusion in multiscale porous particles: Application in battery separators. ACS Applied Materials and Interfaces, 7, 4511-4517 (2015). https://doi.org/10.1021/am506797d

[38] Yoneda H., Nishimura Y., Doi Y., Fukuda M., Kohno M.: Development of microporous PE films to improve lithium ion batteries. Polymer Journal, 42, 425-437 (2010). https://doi.org/10.1038/pj.2010.25

[39] Jeong Y-B., Kim D-W.: Effect of thickness of coating layer on polymer-coated separator on cycling performance of lithium-ion polymer cells. Journal of Power Sources, 128, 256-262 (2004). https://doi.org/10.1016/j.jpowsour.2003.09.073 
[40] Zhu X., Jiang X., Ai X., Yang H., Cao Y.: A highly thermostable ceramic-grafted microporous polyethylene separator for safer lithium-ion batteries. ACS Applied Materials and Interfaces, 7, 24119-24126 (2015). https://doi.org/10.1021/acsami.5b07230

[41] Singh V. P., Vimal K. K., Sharma S., Kapur G. S., Choudhary V.: Polyethylene/sepiolite clay nanocomposites: Effect of clay content, compatibilizer polarity, and molar mass on viscoelastic and dynamic mechanical properties. Journal of Applied Polymer Science, 134, 45197/1-45197/13 (2017).

https://doi.org/10.1002/app.45197

[42] Shafiq M., Yasin T., Saeed S.: Synthesis and characterization of linear low-density polyethylene/sepiolite nanocomposites. Journal of Applied Polymer Science, 123, 1718-1723 (2012). https://doi.org/10.1002/app.34633

[43] Mir S., Yasin T., Halley P. J., Siddiqi H. M., Ozdemir O., Nguyen A.: Thermal and rheological effects of sepiolite in linear low-density polyethylene/starch blend. Journal of Applied Polymer Science, 127, 1330-1337 (2013). https://doi.org/10.1002/app.37657

[44] Zhang Q-R., Li S-X., Hu X-P., Wang P-J., Zeng J-B., Wang X-L., Wang Y-Z.: Structure, morphology, and properties of LDPE/sepiolite nanofiber nanocomposite. Polymers for Advanced Technologies, 28, 958-964 (2017). https://doi.org/10.1002/pat.3703

[45] Bilotti E., Zhang R., Deng H., Quero F., Fischer H. R., Peijs T.: Sepiolite needle-like clay for PA6 nanocomposites: An alternative to layered silicates? Composites Science and Technology, 69, 2587-2595 (2009). http://doi.org/10.1016/j.compscitech.2009.07.016

[46] Deng C., Jiang Y., Fan Z., Zhao S., Ouyang D., Tan J., Zhang P., Ding Y.: Sepiolite-based separator for advanced Li-ion batteries. Applied Surface Science, 484, 446-452 (2019).

https://doi.org/10.1016/j.apsusc.2019.04.141

[47] Mulders J. J. P. A., Oelkers E. H.: An experimental study of sepiolite dissolution rates and mechanisms at $25^{\circ} \mathrm{C}$. Geochimica et Cosmochimica Acta, 270, 296312 (2020).

https://doi.org/10.1016/j.gca.2019.11.026

[48] Taimur S., Hassan M. I., Yasin T.: Removal of copper using novel amidoxime based chelating nanohybrid adsorbent. European Polymer Journal, 95, 93-104 (2017). https://doi.org/10.1016/j.eurpolymj.2017.08.004

[49] Carrero A., van Grieken R., Suarez I., Paredes B.: Development of a new synthetic method based on in situ strategies for polyethylene/clay composites. Journal of Applied Polymer Science, 126, 987-997 (2012). https://doi.org/10.1002/app.36830

[50] Sengupta R., Chakraborty S., Bandyopadhyay S., Dasgupta S., Mukhopadhyay R., Auddy K., Deuri A. S.: A short review on rubber/clay nanocomposites with emphasis on mechanical properties. Polymer Engineering and Science, 47, 1956-1974 (2007).

https://doi.org/10.1002/pen.20921
[51] Farshchi N., Ostad Y. K.: Sepiolite as a nanofiller to improve mechanical and thermal behavior of recycled high-density polyethylene. Progress in Rubber, Plastics and Recycling Technology, 36, 185-195 (2020). https://doi.org/10.1177/1477760620918596

[52] Pan R., Sun R., Wang Z., Lindh J., Edström K., Strømme M., Nyholm L.: Sandwich-structured nano/micro fiberbased separators for lithium metal batteries. Nano Energy, 55, 316-326 (2019).

https://doi.org/10.1016/j.nanoen.2018.11.005

[53] Wang Z., Yu W., Zhou C.: Preparation of polyethylene microporous membranes with high water permeability from thermally induced multiple phase transitions. Polymer, 56, 535-544 (2015).

https://doi.org/10.1016/j.polymer.2014.11.032

[54] Liu J., Li W., Zuo X., Liu S., Li Z.: Polyethylene-supported polyvinylidene fluoride-cellulose acetate butyrate blended polymer electrolyte for lithium ion battery. Journal of Power Sources, 226, 101-106 (2013). https://doi.org/10.1016/j.jpowsour.2012.10.078

[55] Lee Y., Park J., Jeon H., Yeon D., Kim B-H., Cho K. Y., Ryou M-H., Lee Y. M.: In-depth correlation of separator pore structure and electrochemical performance in lithium-ion batteries. Journal of Power Sources, 325, 732738 (2016).

https://doi.org/10.1016/j.jpowsour.2016.06.094

[56] Hojati S., Khademi H.: Thermal behavior of a natural sepiolite from Northeastern Iran. Journal of Sciences, Islamic Republic of Iran, 24, 129-134 (2013).

[57] Li Y., Pu H.: Facile fabrication of multilayer separators for lithium-ion battery via multilayer coextrusion and thermal induced phase separation. Journal of Power Sources, 384, 408-416 (2018).

https://doi.org/10.1016/j.jpowsour.2018.02.086

[58] Singh V. P., Kapur G. S., Shashikant, Choudhary V.: High-density polyethylene/needle-like sepiolite clay nanocomposites: Effect of functionalized polymers on the dispersion of nanofiller, melt extensional and mechanical properties. RSC Advances, 6, 59762-59774 (2016). https://doi.org/10.1039/C6RA08124J

[59] Li W., Li S., Cheng Z., Hu X., Yang W., Yao Y.: The effect of flame retardant-modified sepiolite nanofibers on thermal degradation and fire retardancy of low-density polyethylene. Journal of Thermal Analysis and Calorimetry, 138, 1011-1019 (2019).

https://doi.org/10.1007/s10973-019-08162-3

[60] Ulaganathan M., Lei L., Flora H., Yan Q.: Charge transport, mechanical and storage performances of sepiolite based composite polymer electrolytes. ChemistrySelect, 1, 5821-5827 (2016). https://doi.org/10.1002/slct.201601121

[61] Shi J-L., Fang L-F., Li H., Zhang H., Zhu B-K., Zhu LP.: Improved thermal and electrochemical performances of PMMA modified PE separator skeleton prepared via dopamine-initiated ATRP for lithium ion batteries. Journal of Membrane Science, 437, 160-168 (2013). https://doi.org/10.1016/j.memsci.2013.03.006 
[62] Quartarone E., Mustarelli P.: Electrolytes for solid-state lithium rechargeable batteries: Recent advances and perspectives Chemical Society Reviews, 40, 25252540 (2011)

https://doi.org/10.1039/C0CS00081G

[63] Ryou M-H., Lee Y. M., Park J-K., Choi J. W.: Musselinspired polydopamine-treated polyethylene separators for high-power Li-ion batteries. Advanced Materials, 23, 3066-3070 (2011).

https://doi.org/10.1002/adma.201100303

[64] Wang Y., Yin C., Song Z., Wang Q., Lan Y., Luo J., Bo L., Yue Z., Sun F., Li X.: Application of PVDF organic particles coating on polyethylene separator for lithium ion batteries. Materials, 12, 3125/1-3125/13 (2019). https://doi.org/10.3390/ma12193125
[65] Nunes-Pereira J., Kundu M., Gören A., Silva M. M., Costa C. M., Liu L., Lanceros-Méndez S.: Optimization of filler type within poly(vinylidene fluoride-co-trifluoroethylene) composite separator membranes for improved lithium-ion battery performance. Composites Part B: Engineering, 96, 94-102 (2016).

https://doi.org/10.1016/j.compositesb.2016.04.041

[66] Yang P., Zhang P., Shi C., Chen L., Dai J., Zhao J.: The functional separator coated with core-shell structured silica-poly(methyl methacrylate) sub-microspheres for lithium-ion batteries. Journal of Membrane Science, 474, 148-155 (2015).

https://doi.org/10.1016/j.memsci.2014.09.047 